\title{
Serum anti-DIDO1, anti-CPSF2, and anti- FOXJ2 antibodies as predictive risk markers for acute ischemic stroke
}

Takaki Hiwasa ${ }^{1,2,3^{*}}$ (D) Hao Wang ${ }^{2,4}$, Ken-ichiro Goto², Seiichiro Mine ${ }^{1,5,6}$, Toshio Machida ${ }^{1,6,7}$, Eiichi Kobayashi 1,3, Yoichi Yoshida ${ }^{1,3}$, Akihiko Adachi ${ }^{1,3}$, Tomoo Matsutani $^{1,3}$, Mizuki Sata ${ }^{8,9}$, Kazumasa Yamagishi $^{8}$, Hiroyasu Iso ${ }^{10}$, Norie Sawada ${ }^{11}$, Shoichiro Tsugane ${ }^{11}$, Mitoshi Kunimatsu ${ }^{12}$, Ikuo Kamitsukasa ${ }^{13,14}$, Masahiro Mori ${ }^{15}$, Kazuo Sugimoto 1,15, Akiyuki Uzawa ${ }^{3,15}$, Mayumi Muto ${ }^{15}$, Satoshi Kuwabara ${ }^{3,15}$, Yoshio Kobayashi ${ }^{16}$, Mikiko Ohno ${ }^{17,18}$, Eiichiro Nishi ${ }^{17,18}$, Akiko Hattori ${ }^{19}$, Masashi Yamamoto ${ }^{19}$, Yoshiro Maezawa ${ }^{19}$, Kazuki Kobayashi ${ }^{19}$, Ryoichi Ishibashi ${ }^{19}$, Minoru Takemoto ${ }^{19,20}$, Koutaro Yokote ${ }^{19}$, Hirotaka Takizawa ${ }^{21}$, Takashi Kishimoto ${ }^{22}$, Kazuyuki Matsushita ${ }^{23}$, Sohei Kobayashi ${ }^{23,24}$, Fumio Nomura ${ }^{25}$, Takahiro Arasawa ${ }^{2,26}$, Akiko Kagaya ${ }^{26}$, Tetsuro Maruyama ${ }^{26}$, Hisahiro Matsubara ${ }^{26}$, Minako Tomiita ${ }^{27}$, Shinsaku Hamanaka ${ }^{28}$, Yushi Imai ${ }^{28}$, Tomoo Nakagawa ${ }^{28}$, Naoya Kato ${ }^{28}$, Jiro Terada ${ }^{29}$, Takuma Matsumura ${ }^{29}$, Yusuke Katsumata ${ }^{29}$, Akira Naito ${ }^{29}$, Nobuhiro Tanabe ${ }^{29,30}$, Seiichiro Sakao ${ }^{29}$, Koichiro Tatsumi ${ }^{29}$, Masaaki Ito ${ }^{31}$, Fumiaki Shiratori ${ }^{31}$, Makoto Sumazaki ${ }^{31}$, Satoshi Yajima ${ }^{31}$, Hideaki Shimada ${ }^{31}$, Mikako Shirouzu ${ }^{32}$, Shigeyuki Yokoyama ${ }^{33}$, Takashi Kudo ${ }^{34}$, Hirofumi Doi ${ }^{34}$, Katsuro Iwase ${ }^{2}$, Hiromi Ashino ${ }^{2}$, Shu-Yang Li ${ }^{1,2}$, Masaaki Kubota' ${ }^{1}$, Go Tomiyoshi ${ }^{2,35}$, Natsuko Shinmen ${ }^{2,35}$, Rika Nakamura ${ }^{2,35}$, Hideyuki Kuroda ${ }^{35}$ and Yasuo Iwadate ${ }^{1,3}$

\section{Abstract}

Background: Acute ischemic stroke (AIS) is a serious cause of mortality and disability. AlS is a serious cause of mortality and disability. Early diagnosis of atherosclerosis, which is the major cause of AIS, allows therapeutic intervention before the onset, leading to prevention of AIS.

Methods: Serological identification by CDNA expression cDNA libraries and the protein array method were used for the screening of antigens recognized by serum IgG antibodies in patients with atherosclerosis. Recombinant proteins or synthetic peptides derived from candidate antigens were used as antigens to compare serum lgG levels between healthy donors (HDs) and patients with atherosclerosis-related disease using the amplified luminescent proximity homogeneous assay-linked immunosorbent assay.

(Continued on next page)

\footnotetext{
* Correspondence: hiwasa_takaki@faculty.chiba-u.jp

'Department of Neurological Surgery, Graduate School of Medicine, Chiba University, Chiba 260-8670, Japan

${ }^{2}$ Department of Biochemistry and Genetics, Graduate School of Medicine, Chiba University, Chiba 260-8670, Japan

Full list of author information is available at the end of the article
}

C C The Author(s). 2021 Open Access This article is licensed under a Creative Commons Attribution 4.0 International License, which permits use, sharing, adaptation, distribution and reproduction in any medium or format, as long as you give appropriate credit to the original author(s) and the source, provide a link to the Creative Commons licence, and indicate if changes were made. The images or other third party material in this article are included in the article's Creative Commons licence, unless indicated otherwise in a credit line to the material. If material is not included in the article's Creative Commons licence and your intended use is not permitted by statutory regulation or exceeds the permitted use, you will need to obtain permission directly from the copyright holder. To view a copy of this licence, visit http://creativecommons.org/licenses/by/4.0/. The Creative Commons Public Domain Dedication waiver (http://creativecommons.org/publicdomain/zero/1.0/) applies to the data made available in this article, unless otherwise stated in a credit line to the data. 
(Continued from previous page)

Results: The first screening using the protein array method identified death-inducer obliterator 1 (DIDO1), forkhead box J2 (FOXJ2), and cleavage and polyadenylation specificity factor (CPSF2) as the target antigens of serum IgG antibodies in patients with AIS. Then, we prepared various antigens including glutathione S-transferase-fused DIDO1 protein as well as peptides of the amino acids 297-311 of DIDO1, 426-440 of FOXJ2, and 607-621 of CPSF2 to examine serum antibody levels. Compared with HDs, a significant increase in antibody levels of the DIDO1 protein and peptide in patients with AIS, transient ischemic attack (TIA), and chronic kidney disease (CKD) but not in those with acute myocardial infarction and diabetes mellitus (DM). Serum anti-FOXJ2 antibody levels were elevated in most patients with atherosclerosis-related diseases, whereas serum anti-CPSF2 antibody levels were associated with AIS, TIA, and DM. Receiver operating characteristic curves showed that serum DIDO1 antibody levels were highly associated with CKD, and correlation analysis revealed that serum anti-FOXJ2 antibody levels were associated with hypertension. A prospective case-control study on ischemic stroke verified that the serum antibody levels of the DID01 protein and DIDO1, FOXJ2, and CPSF2 peptides showed significantly higher odds ratios with a risk of AIS in patients with the highest quartile than in those with the lowest quartile, indicating that these antibody markers are useful as risk factors for AIS.

Conclusions: Serum antibody levels of DIDO1, FOXJ2, and CPSF2 are useful in predicting the onset of atherosclerosisrelated AIS caused by kidney failure, hypertension, and DM, respectively.

Keywords: Acute ischemic stroke, Antibody biomarker, Atherosclerosis, Acute myocardial infarction, Diabetes mellitus, Chronic kidney disease

\section{Background}

Atherosclerosis is a serious disease and a major cause of acute ischemic stroke (AIS) and acute myocardial infarction (AMI) [1]. Diabetes mellitus (DM) and chronic kidney disease (CKD) are closely related to and accompanied by atherosclerosis [2]. As atherosclerosis progresses, atherosclerotic plaques are formed on artery walls by foam cells, which are differentiated from smooth muscle cells or macrophages [3-5]. Diagnosing atherosclerosis is important to prevent the onset of AIS and AMI because the effectiveness of treatment and therapy is limited after their onset. Thus, to date, many risk factors and biomarkers including family history, age, obesity, smoking habit, dyslipidemia, hypertension, sleep, C-reactive protein level, interleukin-6 level, troponin level, and B-type natriuretic peptide level have been reported [6, 7]; however, they are still insufficient. Genome-wide association studies on stroke have identified many genes such as NOTCH3 [8], CSTA [9], and COL3A1 [10]. However, lifestyle diseases such as stroke and atherosclerosis can be prevented by improving individuals' lifestyles.

Recent studies have discovered that the development of autoantibodies is not limited to autoimmune diseases but is also observed in other diseases. Some examples include autoantibody markers against proteins such as p53, NY-ESO-1, and RALA for cancer [11-14]; Hsp60 for stroke [15]; insulin [16], glutamic acid decarboxylase [17], and protein tyrosine phosphatase IA-2 [18, 19] for DM, as well as phospholipid [20], apolipoprotein A1 [21, 22], oxidized low-density lipoprotein [22, 23], and heat shock proteins $[22,24]$ for cardiovascular disease (CVD).
Previously, we searched for antibody markers using serological identification of antigens by cDNA expression cloning (SEREX) and the protein array method, and we reported on autoantibodies against Trop2/TACSTD2 [25], TRIM21 [26], Makorin 1 [27], and ECSA [28], for esophageal squamous cell carcinoma; FIR/PUF60 for colon cancer [29]; SH3GL1 [30] and filamin C [31] for glioma; EP300-interacting inhibitor of differentiation 3 for nonfunctional pancreatic neuroendocrine tumors [32]; proline-rich 13 for ulcerative colitis [33]; talin-1 for multiple sclerosis [34]; PSMA7 for amyotrophic lateral sclerosis [35]; NBL1/DAN [36] and SNX16 [37] for obstructive sleep apnea (OSA); and EXD2 for chronic thromboembolic pulmonary hypertension (CTEPH) [38]. We also reported on autoantibody markers for atherosclerosisrelated diseases, e.g., RPA2 [39], PDCD11 [40], MMP1 [41], and DNAJC2 [42] for AIS; ASXL2 [43] for atherosclerosis; and nardilysin for acute coronary syndrome [44]. Here, we report on antibodies against death-inducer obliterator 1 (DIDO1), forkhead box J2 (FOXJ2), and cleavage and polyadenylation specificity factor (CPSF2) peptides, which are highly associated with AIS and could be useful as predictive markers.

\section{Methods}

The data that support the findings of this study are available from the corresponding author upon reasonable request.

\section{Patient and controls}

This study was approved by the Local Ethical Review Board of the Chiba University Graduate School of 
Medicine (Chiba, Japan) as well as the review boards of the cooperating hospitals or institutes. Sera were collected from patients who had provided informed consent. Each serum sample was centrifuged at $3000 \mathrm{~g}$ for $10 \mathrm{~min}$, and supernatant was stored at $-80^{\circ} \mathrm{C}$ until use. Repeated freezing and thawing of samples was avoided.

Serum samples from patients with DM, ulcerative colitis, CTEPH, pulmonary arterial hypertension (PAH), and OSA were obtained from Chiba University Hospital, and samples collected from patients with AIS, transient ischemic attack (TIA), asymptomatic cerebral infarction (asympt-CI), chronic-phase CI (cCI), and deep and subcortical white matter hyperintensity (DSWMH) were obtained from Chiba Prefectural Sawara Hospital, Chiba Rosai Hospital, Chiba Aoba Municipal Hospital, and Chiba Medical Center. The stroke subtype of each patient was also determined according to the criteria of the Trial of Org 10172 in Acute Stroke Treatment classification system [45]. In this analysis, large-artery atherosclerosis or small-artery occlusion (lacune) were included as AIS or cerebral infarction.

Serum samples from patients with AIS used in the preliminary screening were provided by BioBank Japan. Serum samples from patients with AMI were obtained from Kyoto University Hospital [44]. Serum samples associated with AIS, TIA, and AMI were obtained within 2 weeks after disease onset. Samples collected from patients with CKD were obtained from the Kumamoto cohort $[46,47]$, whereas those collected from patients with colorectal carcinoma, esophageal squamous cell carcinoma, gastric cancer, breast cancer, and pancreatic cancer were obtained from the Department of Frontier Surgery, Chiba University Hospital. Serum samples from patients with Sjögren's syndrome were obtained from Chiba Children's Hospital. Serum samples from patients with rheumatoid arthritis and systemic lupus erythematosus (SLE) were obtained from the National Hospital Organization, Shimoshizu Hospital, and Chiba East Hospital [48]. Serum samples from healthy donors (HDs) were obtained from Chiba University, Port Square Kashiwado Clinic, Higashi Funabashi Hospital, and Chiba Prefectural Sawara Hospital. For comparisons with TIA and AIS, serum samples from HDs were selected from patients who exhibited no abnormalities on cranial magnetic resonance imaging.

\section{ProtoArray screening}

The first screening was performed using ProtoArray Human Protein Microarrays v. 4.0 (Thermo Fisher Scientific, Waltham, MA), which were loaded with 9480 proteins species as described previously [33, 38, 48]. In total, 30 serum samples (15 each from HDs and patients with atherosclerosis) were used to detect antigens specifically recognized by IgG antibodies in sera. Results were analyzed using the Prospector software (Thermo Fisher Scientific), which is based on M-statistics. When comparing the two groups, a cutoff for positivity was calculated for each protein using M-statistics. For both groups, the proportion of subjects with an immune response above the cutoff value was counted, and a $P$ value representing the significance of the difference between both groups was calculated as described [49].

\section{Expression and purification of the DIDO1 protein}

Total RNA was isolated from human U2OS osteosarcoma cells using the High Pure RNA Isolation Kit (Roche, Basel, Switzerland), and cDNA was synthesized using the SuperScript III First-Strand Synthesis System for RT-PCR (Thermo Fisher Scientific). The aminoterminal (amino acids 1-275) and carboxy-terminal half (amino acids 271-545) of the coding sequences of DIDO1 cDNA were amplified via PCR using Pyrobest DNA polymerase (Takara Bio Inc., Shiga, Japan) and cloned at the EcoRI/SalI site of pGEX-4 T-3 (GE Healthcare Life Sciences, Pittsburgh, PA), followed by confirmation by DNA sequencing. Expression of the cDNA product was induced by treating pGEX-4 T-3-DIDO1transformed Escherichia coli (E. coli) with $0.1 \mathrm{mM}$ isopropyl- $\beta$-D-thiogalactoside at $25^{\circ} \mathrm{C}$ for $4 \mathrm{~h}$; the cells were subsequently lysed in BugBuster ${ }^{\circledR}$ Master Mix (Merck Millipore, Darmstadt, Germany). Then, glutathione S-transferase (GST)-tagged DIDO1 protein was purified by glutathione-Sepharose (GE Healthcare Life Sciences) column chromatography according to the manufacturer's instructions and dialyzed against phosphate-buffered saline (PBS) as described previously [34-37, 39-43].

\section{Western blotting}

GST-tagged amino-terminal (amino acids 1-275) and carboxy-terminal half (amino acids 271-545) DIDO1 proteins were designated as $\mathrm{DIDO}_{\mathrm{N}}$ and $\mathrm{DIDO} 1_{\mathrm{C}}$, respectively, and purified as described above. GST-FOXJ2 and GST-CPSF2 were purchased from Abnova (Taipei, Taiwan). GST and GST fusion proteins $(0.3 \mu \mathrm{g})$ were separated via sodium dodecyl sulfate-polyacrylamide gel electrophoresis and electrically transferred onto nitrocellulose membranes (Advantec, Tokyo, Japan). The membranes were blocked using a blocking solution $[0.5 \%$ skim milk powder in a buffer comprising $20 \mathrm{mM}$ Tris$\mathrm{HCl}$ (pH 7.6), $137 \mathrm{mM} \mathrm{NaCl}$, and 0.1\% Tween 20], and the blotted proteins were probed with primary antibodies including anti-GST (goat) (Rockland, Gilbertsville, PA), anti-DIDO1 (rabbit) (Aviva Systems Biology, San Diego, CA), or anti-FOXJ2 (rabbit) (Thermo Fisher Scientific), anti-CPSF2 (rabbit) (GeneTex, Irvine, CA) or from sera from HDs (\#30017) or patients with TIA 
(\#07060, \#07175, and \#07207) or AIS (\#07115, \#07581, and \#07684). After incubation with horseradish peroxidase-conjugated secondary antibodies (anti-goat IgG, anti-rabbit IgG, and antihuman IgG; Santa Cruz Biotechnology, Santa Cruz, CA), immunoreactivity was determined with Immobilon ${ }^{\text {тм }}$ Western HRP Substrate (Merck KGaA, Darmstadt, Germany) as previously described [25-30, 39-43].

\section{Epitope prediction and peptide synthesis}

Possible epitope sites in the CPSF2 and FOXJ2 proteins were predicted using the ProPred program (http://www. imtech.res.in/raghava/propred/) as described previously $[38,48]$. The following amino acid sequences were designed:

bCPSF3-165: biotin-FMIEIAGVKLLYTGD
bCPSF3-298: biotin-NINNPFVFKHISNLK
bCPSF3-545: biotin-KPALKVFKNITVIQE
bCPSF2-607: biotin-QVRLKDSLVSSLQFC
bCPSF2-712: biotin-QSVFMNEPRLSDFKQ
bFOXJ2-426: biotin-KMVNRLNWSSIEQSQ

\section{Peptide array method}

The epitopes in the DIDO1 protein were screened comprehensively throughout the full-length DIDO1 protein using the peptide array method, in which we designed 83 peptides of 14 mer derived from the DIDO1 protein. These peptides were synthesized onto cellulose membranes using Fmoc amino acids (Auto-Spot Robot ASP222; ABIMED Analysen-Technik GmbH, Langenfeld, Germany) as described previously [50]. The membranes were washed five times with PBS containing 1\% $(\mathrm{w} / \mathrm{v})$ bovine serum albumin, $0.05 \%$ Tween 20, and $0.05 \% \mathrm{NaN}_{3}$ (PBS-T-BSA) for $30 \mathrm{~min}$ each and then incubated with a 1:200 dilution of sera of HDs or patients with AIS for $18 \mathrm{~h}$. The membranes were subsequently washed five times with PBS-T-BSA and treated with a 1: 10,000 dilution of FITC-conjugated goat antihuman IgG (Jackson ImmunoResearch, West Grove, PA) for $1 \mathrm{~h}$. After washing, the fluorescence levels of peptide spots were detected using the Typhoon 9400 Imager (GE Healthcare Life Sciences) with a 488-nm/520-nm filter, as described previously $[30,48,51]$.

\section{Peptide synthesis}

$\mathrm{N}$-terminal biotinylated 15-mer peptide of amino acids 426-440 derived from FOXJ2 (designated as bFOXJ2426), N-terminal biotinylated 15-mer peptide of amino acids 607-621 derived from CPSF2 (designated as bCPSF2-607), and N-terminal biotinylated 18-mer peptide of amino acids 297-314 derived from DIDO1 (designated as bDIDO1-297) were purchased from Eurofins
Genomics (Tokyo, Japan). Their amino acid sequences and purity were as follows:

\section{bFOXJ2-426: biotin-KMVNRLNWSSIEQSQ (94.9\%) \\ bCPSF2-607: biotin-QVRLKDSLVSSLQFC (99.2\%) \\ bDIDO1-297: biotin-AMAASKKTAPPGSAVGKQ \\ $(98.4 \%)$}

\section{Amplified luminescent proximity homogeneous assay- linked immunosorbent assay (AlphaLISA)}

AlphaLISA was performed in 384-well microtiter plates (white opaque OptiPlate ${ }^{\mathrm{Ts}}$; PerkinElmer, Waltham, MA) containing either $2.5 \mu \mathrm{L}$ of 1:100 diluted serum with $2.5 \mu \mathrm{L}$ of GST or GST-DIDO1 protein $(10 \mu \mathrm{g} / \mathrm{mL})$ or biotinylated peptides (bDIDO1-297, bFOXJ2-426, and bCPSF2-607; $400 \mathrm{ng} / \mathrm{mL}$ ) in AlphaLISA buffer (25 mM HEPES, pH 7.4; $0.1 \%$ casein, $0.5 \%$ Triton X-100, $1 \mathrm{mg} /$ mL Dextran 500, and $0.05 \%$ ProClin 300). The reaction mixture was incubated at room temperature for $6-8 \mathrm{~h}$, after which antihuman IgG-conjugated acceptor beads $(2.5 \mu \mathrm{L}$ at $40 \mu \mathrm{g} / \mathrm{mL})$ and glutathione- or streptavidinconjugated donor beads $(2.5 \mu \mathrm{L}$ at $40 \mu \mathrm{g} / \mathrm{mL})$ were added and incubated, followed by another incubation at room temperature in the dark for 1-14 days. Chemical emissions were read on an EnSpire Alpha microplate reader (PerkinElmer) as described previously [32-38, 40-43, 48, 51]. Specific reactions were calculated by subtracting the Alpha counts of GST control and buffer control without antigenic peptides from the counts of GST-fusion proteins and biotinylated peptides, respectively.

\section{Immunohistochemical staining}

Tissue samples were obtained from surgically resected carotid atherosclerotic plaques. Paraffin-embedded vascular tissues were sectioned and then dewaxed using graded alcohol and xylene. After antigen retrieval at $98^{\circ} \mathrm{C}$ for $40 \mathrm{~min}$ in $10 \mathrm{mM}$ citrate buffer ( $\mathrm{pH}$ 6.0), endogenous peroxidase was blocked using 3\% hydrogen peroxide in methanol for $30 \mathrm{~min}$. Then, all sections were washed three times with a wash buffer (S3006; Agilent, Santa Clara, CA) for $5 \mathrm{~min}$ each and incubated for $1 \mathrm{~h}$ with antihuman DIDO1 antibody (rabbit; Aviva Systems Biology), anti-FOXJ2 antibody (rabbit; Thermo Fisher Scientific), anti-CPSF2 antibody (rabbit; GeneTex), antiDHPS antibody (rabbit; Proteintech, Rosemont, IL), antivimentin antibody (mouse; Agilent), anti-smooth muscle actin antibody (mouse; Agilent), anti-CD31 antibody (mouse; Agilent), anti-CD68 antibody (mouse; Agilent), and anti-CD34 antibody (mouse; Agilent) at $2 \mu \mathrm{g} / \mathrm{mL}$ at $37^{\circ} \mathrm{C}$ for $60 \mathrm{~min}$. Subsequently, the sections were washed three times with a wash buffer (S3006) for 5 min each and then incubated with horseradish peroxidaseconjugated anti-rabbit/anti-mouse secondary antibodies (EnVision $^{\text {тм }}$ Detection System:, K5007; Agilent) at $37^{\circ} \mathrm{C}$ 
for $60 \mathrm{~min}$. The bound antibodies were visualized with chromogen diaminobenzidine in $3 \%$ hydrogen peroxidase. Finally, the sections were counterstained with hematoxylin, dehydrated, and mounted on glass slides as described in the literature [25, 28, 39].

\section{Nested case-control study}

A nested case-cohort study was conducted using the abovementioned AlphaLISA detection antibody levels. This study was nested within the Japan Public Health Center (JPHC)-based Prospective Study [52, 53], which involved approximately 30,000 Japanese individuals aged 40-69 years at a baseline period of 1990-1994 whose plasma samples were stored. Serum DIDO1, bDIDO1297, bFOXJ2-426, and bCPSF2-607 antibody levels were measured in 202 cases of incidental AIS in the cohort developed between the baseline and 2008 as well as in 202 controls whose sex, age (within 2 years), date of blood sampling (within 3 months), time since last meal (within $4 \mathrm{~h}$ ), and study location (Public Health Center area) were matched with those of the cases. We used a conditional logistic regression model to estimate odds ratios and 95\% confidence intervals (CIs) for AIS with respect to serum antibody levels of the DIDO1 protein and DIDO1, FOXJ2, and CPSF2 peptides.

\section{Statistical analysis}

Mann-Whitney $U$ test, Student's $t$ test, and KruskalWallis test were used to determine the significance of the differences between two groups or among multiple groups. Correlations were calculated using Spearman's correlation analysis. All statistical analyses were performed using GraphPad Prism 5 (GraphPad Software, La Jolla, CA). The predictive values of putative disease markers were assessed using a receiver operating characteristic (ROC) curve analysis, and cutoff values were set to maximize the sums of sensitivity and specificity. All tests were two tailed, and $P$ values of $<0.05$ were considered statistically significant.

\section{Results}

Recognition of DIDO1, CPSF2, and FOXJ2 via serum igg antibodies of patients with atherosclerosis

The first screening for AIS biomarkers was performed using SEREX and the protein array method. After the second screening using serum samples from HDs obtained from Chiba University Hospital and serum samples from patients with AIS obtained from BioBank Japan, we identified 74 antibody markers for AIS, some of which have been reported previously (Table 1). Preliminary validation tests using serum samples from patients with AIS obtained from BioBank Japan showed that the antibody levels against these three antigens, DIDO1, FOXJ2, and CPSF2, were reproducibly and significantly higher in AIS sera than control HD sera. Thus, we focused on three antibody markers highly associated with AIS.

The results of ProtoArray loaded with 9480 protein species showed that DIDO1 (accession no. BC000770.1) antibodies were observed in 4 out of 5 serum samples from patients with atherosclerosis and 1 out of 5 serum samples from HDs. FOXJ2 (accession no. NM_018416.2) antibodies were found to react with antibodies in 7 out of 15 serum samples from patients with atherosclerosis and none of the 15 serum samples from HDs. CPSF2 (100 kDa; accession no. NM_017437.1) antibodies reacted with antibodies in 5 out of 10 serum samples from patients with atherosclerosis and 2 out of 10 serum samples from HDs. Subsequently, GST fusion proteins that contained $\mathrm{DIDO} 1_{\mathrm{N}}$ or $\mathrm{DIDO}_{\mathrm{C}}$ were expressed in $E$. coli and purified via affinity chromatography. In addition, 5 predicted epitopes of CPSF2 and 1 of FOXJ2 were prepared, and the following preliminary experiments showed that serum bFOXJ2-426 and bCPSF2-607 antibody levels more highly reacted with serum antibodies in patients with AIS than with those in HDs. To examine epitopes in the DIDO1 protein recognized by serum antibodies, we synthesized a peptide array [30, 48, 51] loaded with 83 species of 14-mer peptides derived from the DIDO1 protein. bDIDO1-297, which was most closely associated with AIS, was also used as an antigen to evaluate serum antibody levels.

\section{Presence of serum antibodies against purified proteins in patients with TIA or AIS}

We then confirmed the presence of antibodies against the GST fusion proteins of DIDO $1_{\mathrm{N}}, \mathrm{DIDO} 1_{\mathrm{C}}, \mathrm{FOXJ} 2$, and CPSF2 in serum samples from patients with TIA or AIS via Western blotting. GST, GST-DIDO $1_{\mathrm{N}}, \mathrm{GST}-$ DIDO1 $1_{C}, G S T-F O X J 2$, and GST-CPSF2 were recognized by the anti-GST antibody as reactions of 26-, 70-, 57-, 95-, and 110-kDa proteins, respectively (Fig. 1). GST-DIDO1 ${ }_{\mathrm{N}}, \mathrm{GST}-\mathrm{FOXJ} 2$, and GST-CPSF2 were recognized by each specific commercial antibody. GST$\mathrm{DIDO}_{\mathrm{N}}$ and $\mathrm{GST}-\mathrm{DIDO} 1_{\mathrm{C}}$ (but not GST) reacted with antibodies in serum samples from patients with TIA\#07207, AIS-\#07684, TIA-\#07175, and AIS-\#07115, whereas the serum antibodies of patients with AIS\#07684 and TIA-\#07060 recognized GST-DIDO1 ${ }_{\mathrm{N}}$ but not GST-DIDO1 $1_{C}$. GST-CPSF2 reacted with antibodies in serum sample from a patient with TIA-\#07175, and GST-FOXJ2 reacted with antibodies in serum sample from patients with AIS-\#07115 and TIA-\#07060. None of these antigenic proteins were recognized by serum IgG in patients with HD-\#30017. As such, the reactivity of GST fusion antigenic proteins with serum antibodies may be primarily attributed to the antigenic protein regions but not to the GST domain. GST-DIDO1 ${ }_{\mathrm{N}}$ was 
Table 1 List of antibody biomarkers for atherosclerosis

\begin{tabular}{|c|c|c|c|c|}
\hline $\begin{array}{l}\text { Abbreviated } \\
\text { name }\end{array}$ & $\begin{array}{l}\text { Accession } \\
\text { number }\end{array}$ & Full name & $\begin{array}{l}\text { Screening } \\
\text { method }\end{array}$ & Reference \\
\hline$\overline{\mathrm{DIDO} 1}$ & BC000770.1 & Death inducer obliterator-1 & Protein array & $\begin{array}{l}\text { This } \\
\text { report }\end{array}$ \\
\hline CPSF2 & NM_017437.1 & Cleavage and polyadenylation specific factor 2, $100 \mathrm{kDa}$ & Protein array & $\begin{array}{l}\text { This } \\
\text { report }\end{array}$ \\
\hline FOXJ2 & NM_018416.2 & Forkhead box J2 & Protein array & $\begin{array}{l}\text { This } \\
\text { report }\end{array}$ \\
\hline ACTR3B & NM_020445.6 & ARP3 actin-related protein 3 homolog B & SEREX & [40] \\
\hline ADAMTS7 & NM_014272.3 & ADAM metallopeptidase with thrombospondin type 1 motif, 7 & SEREX & \\
\hline AR141352 & NM_133494 & NIMA (never in mitosis gene a)-related kinase 7 & SEREX & \\
\hline ASXL2 & NM_018263.6 & Additional sex combs-like 2 & SEREX & [43] \\
\hline ATP2B4 & $\begin{array}{l}N_{-} \\
001001396.2\end{array}$ & ATPase, $\mathrm{Ca}^{++}$transporting, plasma membrane 4 & Protein array & [54] \\
\hline $\mathrm{BAZ1B}$ & NM_032408 & Bromodomain adjacent to zinc finger domain, 1B & SEREX & \\
\hline BMP1 & NM_006129.4 & Bone morphogenetic protein 1 & SEREX & {$[39,54]$} \\
\hline CBX1 & NM_001127228 & Chromobox homolog 1 & SEREX & {$[41]$} \\
\hline CBX5 & NM_012117 & Chromobox homolog 5 & SEREX & [41] \\
\hline CCNG2 & NM_004354.3 & Cyclin G2 & Protein array & [48] \\
\hline CEP290 & NM_014684 & Centrosomal protein $290 \mathrm{kDa}$ & SEREX & \\
\hline CLDND1 & NM_001040181 & Claudin domain containing 1 & Protein array & [48] \\
\hline COPE & CR456886 & Coatomer protein complex subunit epsilon & SEREX & [36] \\
\hline CRIM1 & NM_016441.2 & Cysteine-rich transmembrane BMP regulator 1 (chordin-like) & SEREX & \\
\hline CTNNA1 & NM_001903.5 & Catenin alpha 1 & SEREX & [40] \\
\hline CTNND1 & NM_001085458 & Catenin delta 1 & Protein array & [48] \\
\hline DEF8 & NM_207514 & Differentially expressed in FDCP 8 homolog (mouse) & SEREX & \\
\hline DHPS & NM_001930 & Deoxyhypusine synthase & Protein array & [55] \\
\hline DNAJA1 & NM_001539 & DnaJ heat shock protein family (Hsp40) member A1 & SEREX & [42] \\
\hline DNAJC2 & NM_014377 & DnaJ heat shock protein family (Hsp40) member C2 & SEREX & [42] \\
\hline DST & NM_015548 & Dystonin & SEREX & \\
\hline EEF1A1 & NM_001402.5 & Eukaryotic translation Elongation factor 1 alpha 1 & SEREX & [56] \\
\hline EEF1G & NM_001404.4 & Eukaryotic translation elongation factor 1 gamma & SEREX & \\
\hline EIF2A & NM_032025.3 & Eukaryotic translation initiation factor $2 \mathrm{~A}, 65 \mathrm{kDa}$ & SEREX & \\
\hline FER1L3 & NM_133337 & Myoferlin & SEREX & \\
\hline GOPC & NM_001017408 & Golgi associated PDZ and coiled-coil motif containing & SEREX & \\
\hline $\mathrm{H} 3 \mathrm{~F} 3 \mathrm{~B}$ & NM_005324 & $\mathrm{H} 3$ histone, family $3 \mathrm{~B}$ & SEREX & \\
\hline HM13 & AF483215 & Histocompatibility (minor) 13 & SEREX & \\
\hline HSPA8 & NM_006597 & Heat shock $70 \mathrm{kDa}$ protein 8 & SEREX & \\
\hline HSPB1 & NM_001540.3 & Heat shock 27 kDa protein 1 & SEREX & \\
\hline KIAA0020 & NM_014878 & KIAA0020 & SEREX & [56] \\
\hline LGALS9 & NM_009587 & Galectin 9 & SEREX & [39] \\
\hline LRPAP1 & NM_002337 & Low-density lipolipoprotein receptor-related protein-associated protein 1 & SEREX & [57] \\
\hline MAGT1 & NM_032121.5 & Magnesium transporter 1 & SEREX & \\
\hline MMP1 & NM_002421 & Metalloproteinase 1 & SEREX & [41] \\
\hline MYBBP1A & NM_001105538 & MYB binding protein 1a & Protein array & [48] \\
\hline NAV2 & NM_145117.4 & Neuron navigator 2 & SEREX & \\
\hline PARC & NM_015089 & p53-associated parkin-like cytoplasmic protein & SEREX & \\
\hline
\end{tabular}


Table 1 List of antibody biomarkers for atherosclerosis (Continued)

\begin{tabular}{|c|c|c|c|c|}
\hline $\begin{array}{l}\text { Abbreviated } \\
\text { name }\end{array}$ & $\begin{array}{l}\text { Accession } \\
\text { number }\end{array}$ & Full name & $\begin{array}{l}\text { Screening } \\
\text { method }\end{array}$ & Reference \\
\hline PDCD11 & NM_014976.2 & Programmed cell death 11 & SEREX & {$[40,58]$} \\
\hline PFKFB3 & NM_004566 & 6-Phosphofructo-2-kinase/Fructose-2,6-biphosphatase 3 & SEREX & \\
\hline PHF20 & NM_016436 & PHD finger protein 20 & SEREX & \\
\hline PPP1R15A & NM_014330 & Protein phosphatase 1 regulatory subunit 15A & SEREX & {$[39,59]$} \\
\hline PRCP & NM_005040.1 & Prolylcarboxypeptidase & Protein array & {$[60]$} \\
\hline PSAP & NM_002778 & Prosaposin & SEREX & \\
\hline RANBP2L1 & NM_005054 & RAN binding protein 2-like 1 & SEREX & \\
\hline RBCK1 & NM_031229 & RanBP-type and C3HC4-type zinc finger containing 1 & SEREX & \\
\hline RBPJ & NM_005349 & Recombination signal binding protein for immunoglobulin kappa J region & SEREX & \\
\hline ROCK1 & NM_005406 & Rho-associated, coiled-coil containing protein kinase 1 & SEREX & \\
\hline RPA1 & NM_002945 & Replication protein A1 & SEREX & \\
\hline RPA2 & NM_002946 & Replication protein A2 & SEREX & [39] \\
\hline RPL3 R & NM_000967 & Ribosomal protein $L 3 t$ & SEREX & \\
\hline SC65 & BC007942 & Synaptonemal complex protein SC65 & SEREX & [39] \\
\hline SH3BP5 & NM_004844 & SH3 domain-binding protein 5 & Protein array & [51] \\
\hline SMARCA4 & NM_001128847 & $\begin{array}{l}\text { SWI/SNF related, matrix associated, actin dependent regulator of chromatin, } \\
\text { subfamily a, member } 4\end{array}$ & SEREX & \\
\hline SNX16 & NM_022133.4 & Sorting Nexins 16 & SEREX & {$[37]$} \\
\hline SOSTDC1 & NM_015464 & Sclerostin domain containing 1 & Protein array & [48] \\
\hline SPARC & NM_003118 & Secreted protein acidic and cysteine-rich & SEREX & \\
\hline SPOCK1 & NM_004598 & SPARC (osteonectin), cwcv and kazal like domains proteoglycan 1 & SEREX & [56] \\
\hline TBC1D2 & NM_001267571 & TBC1 domain family, member 2 & SEREX & \\
\hline TBC1D4 & NM_014832 & TBC1 domain family, member 4 & SEREX & \\
\hline TEX261 & NM_144582 & Testis expressed 261 & SEREX & \\
\hline TFAM & NM_003201 & Transcription factor A, mitochondrial & Protein array & [48] \\
\hline THBS1 & NM_003246 & Thrombospondin 1 & SEREX & \\
\hline TMEFF1 & NM_003692 & Transmembrane protein with EGF-like and two follistatin-like domains 1 & SEREX & \\
\hline TOP3В & NM_003935 & DNA topoisomerase III beta & Protein array & [48] \\
\hline TUBB2C & NM_006088 & Tubulin, beta $2 \mathrm{C}$ & SEREX & {$[56]$} \\
\hline TYMS & NM_001071 & Thymidylate synthetase & SEREX & \\
\hline WDR36 & NM_139281.2 & T cell activation WD repeat protein & SEREX & [39] \\
\hline XPO1 & NM_003400.3 & Exportin 1 & SEREX & \\
\hline XRCC4 & NM_022406 & X-ray repair cross complementing 4 & SEREX & \\
\hline ZFP36L1 & NM_004926 & ZFP36 ring finger protein like 1 & SEREX & \\
\hline
\end{tabular}

recognized by most, if not all, serum samples from patients with AIS and TIA. Thus, in the following experiments, GST-DIDO1 $1_{\mathrm{N}}$, not GST-DIDO1 $1_{\mathrm{C}}$, was used for the measurement of antibody levels.

\section{Elevation of serum DIDO1-Ab, FOXJ2-Ab, and CPSF2-Ab levels in patients with TIA or AIS}

We then examined the levels of anti-DIDO $1_{\mathrm{N}}$ protein, anti-FOXJ2 peptide (bFOXJ2-426), and anti-CPSF2 peptide (bCPSF2-607) antibodies (abbreviated as DIDO1-Ab, FOXJ2-Ab, and CPSF2-Ab, respectively) in serum samples from patients with TIA or AIS. Serum samples from HDs were obtained from the Port Square Kashiwado Clinic and compared with those from patients with TIA and AIS obtained from Chiba Prefectural Sawara Hospital, Chiba Rosai Hospital, Chiba Aoba Municipal Hospital, and Chiba Medical Center. AlphaLISA demonstrated that the serum levels of DIDO1-Ab, FOXJ2-Ab, and CPSF2-Ab were significantly higher in patients with AIS than in HDs (Fig. 2a, g and 3d). DIDO1-Abs and FOXJ2-Abs but not CPSF2-Abs were also elevated in patients with TIA as compared with those in HDs. At a cutoff value of the 


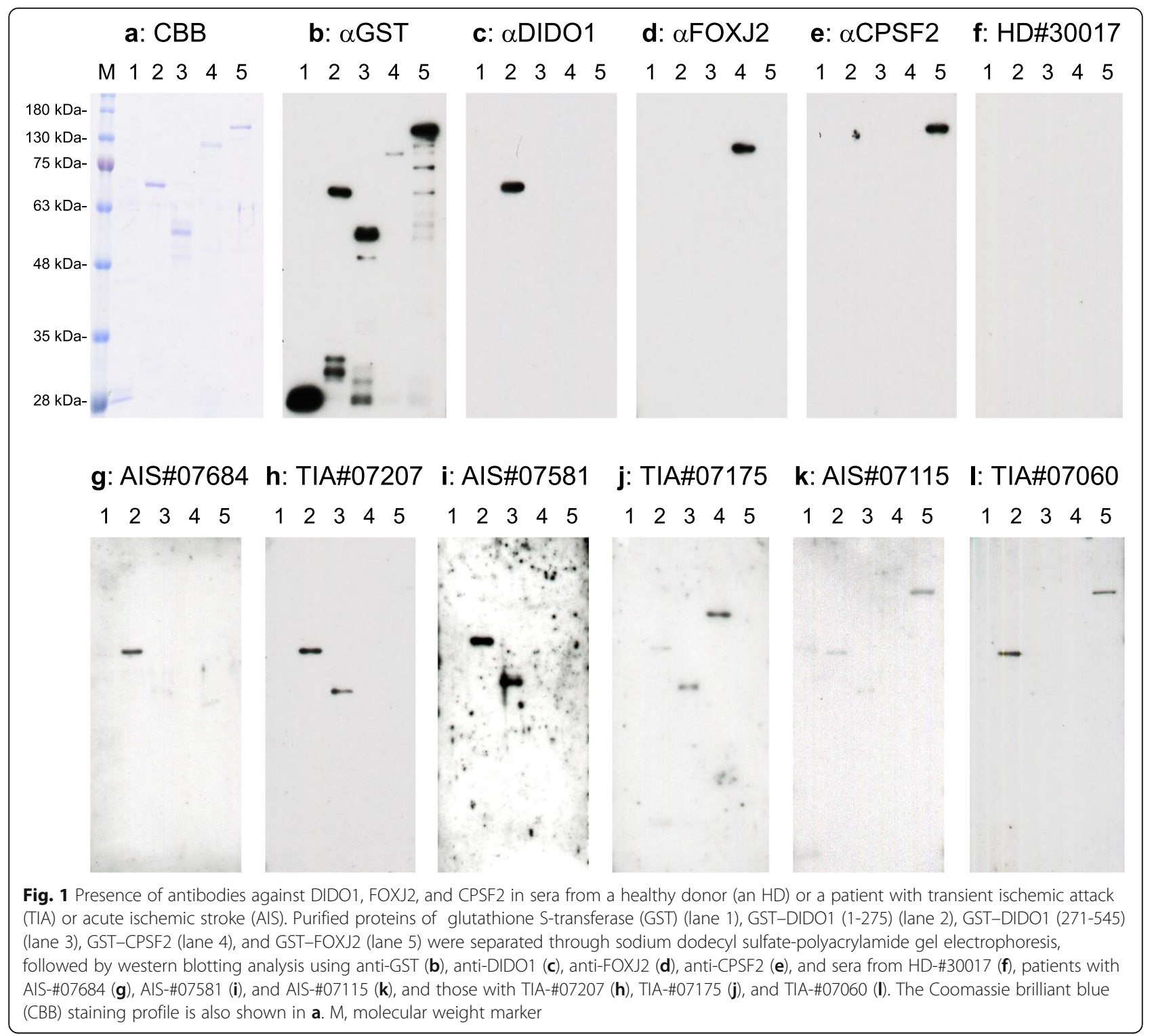

mean HD value plus 2 standard deviation (SD), the DIDO1-Ab positive rate in HDs and patients with TIA, AIS, and cCI was $6.7 \%, 15.2 \%, 17.5 \%$, and $15.4 \%$, respectively (Table 2). Their FOXJ2-Ab and CPSF2-Ab positive rates were $5.6 \%, 14.1 \%, 19.6 \%$, and $20.0 \%$, respectively, and $4.2 \%, 16.3 \%, 14.9 \%$, and $21.5 \%$, respectively.

The serum levels of anti-bDIDO1-297 peptide antibodies (DIDO1pep-Abs) were also higher in patients with TIA and AIS than in HDs (Supplementary Figure S1).

\section{Elevation of serum DIDO1, FOXJ2, and CPSF2 antibody levels in patients with $\mathrm{AMI}$ or DM}

We then examined DIDO1-Ab, FOXJ2-Ab, and CPSF2$\mathrm{Ab}$ in HDs and patients with AMI and DM. Serum samples from patients with AMI were obtained from Kyoto University Hospital, those from patients with DM were obtained from Chiba University Hospital, and those from HDs were obtained from the Port Square Kashiwado Clinic. The mean age $( \pm S D)$ of HDs and patients with AMI and DM was 58.29 \pm 5.63, $58.20 \pm 8.50$, and $58.37 \pm$ 9.11 years, respectively. A total of 128 samples each of HDs and patients with AMI and type 2 DM were assayed simultaneously using AlphaLISA on a 384-well plate. Serum DIDO1-Ab levels were not visibly different between the serum samples from HDs and those from patients with AMI or DM (Fig. 3a). However, serum FOXJ2Ab levels were significantly higher in patients with AMI or DM than in HDs (Fig. 3d). Using cutoff values as described in the previous section, positive rates were $3.1 \%$ in HDs, $34.4 \%$ in patients with AMI, and $22.7 \%$ in those with DM (Table 3). Serum CPSF2-Ab levels were significantly higher in patients with DM (although not in those with 


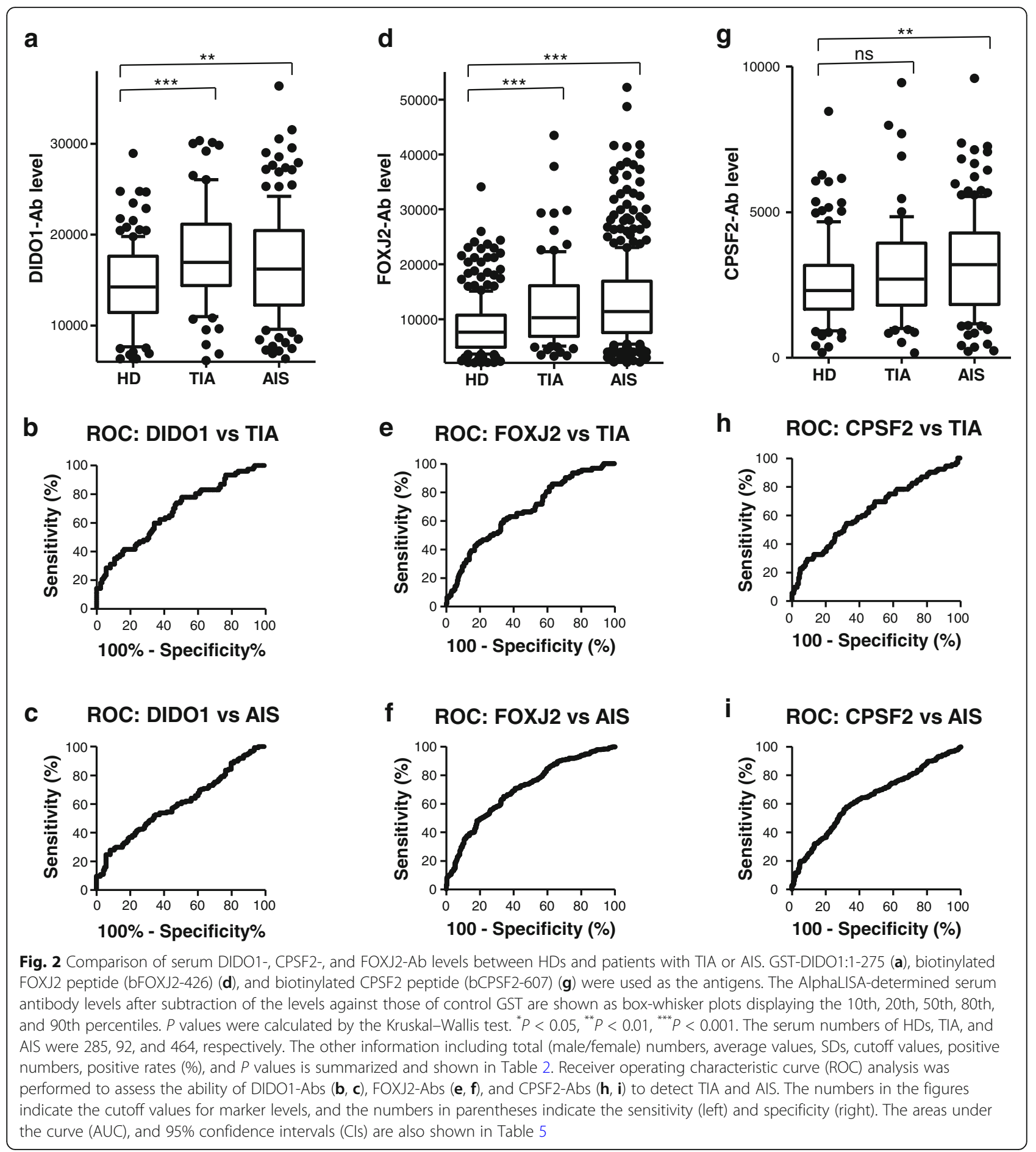

AMI) than in HDs (Fig. 3g). The positive rate of CPSF2-Ab in patients with DM was $13.3 \%$ (Table 2).

Elevation of serum DIDO1, FOXJ2, and CPSF2 antibody levels in patients with CKD

Next, we examined antibody levels in serum samples from patients with CKD, which is also closely related to atherosclerosis. Patients with CKD were divided into three groups: type 1 (diabetic kidney disease), type 2 (nephrosclerosis), and type 3 (glomerulonephritis). Serum samples from patients with CKD were obtained from the Kumamoto cohort and those from HDs were obtained from Chiba University. All CKD groups had significantly higher serum DIDO1-Ab and FOXJ2-Ab levels than HDs (Fig. 4a and e). The positive rates of DIDO1-Ab in HDs and patients with type 1, type 2, and 


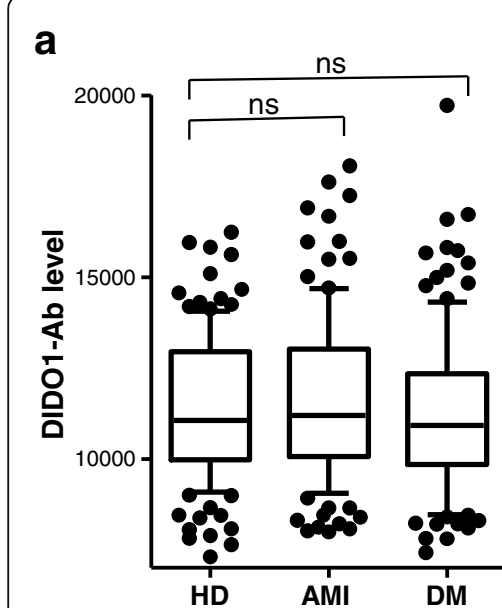

b

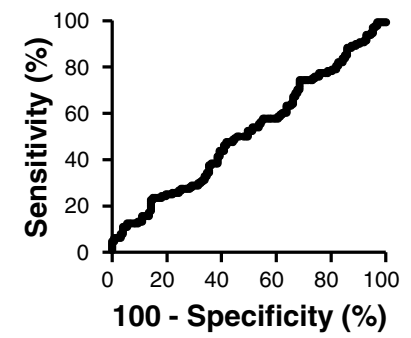

C
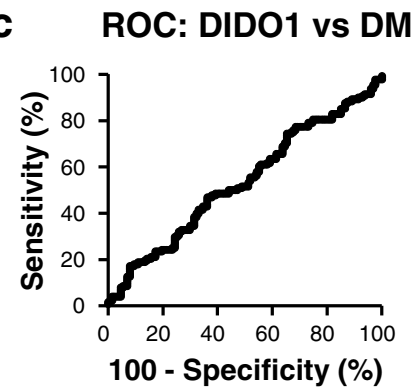

d

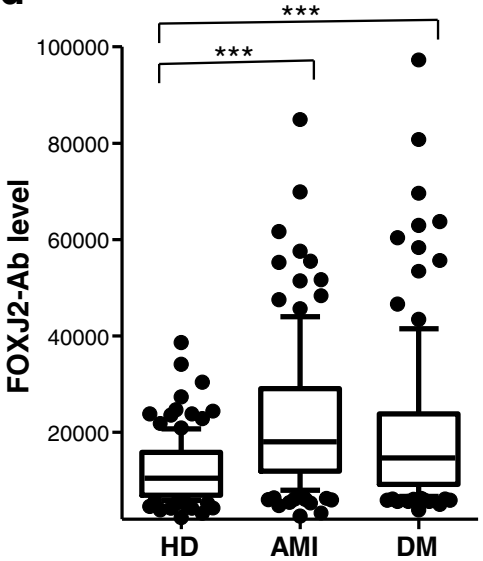

e

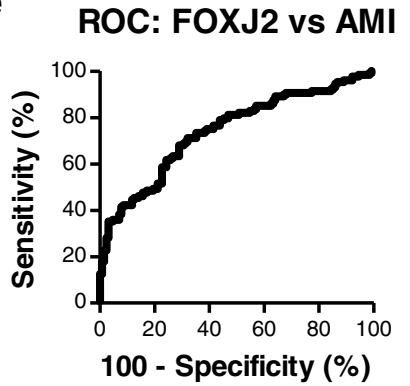

f

ROC: FOXJ2 vs DM

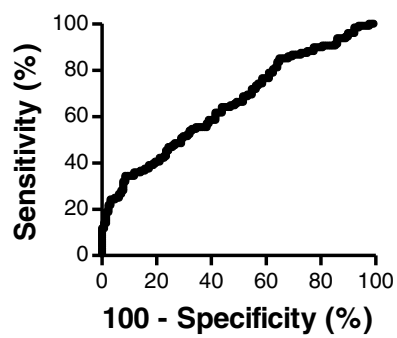

g

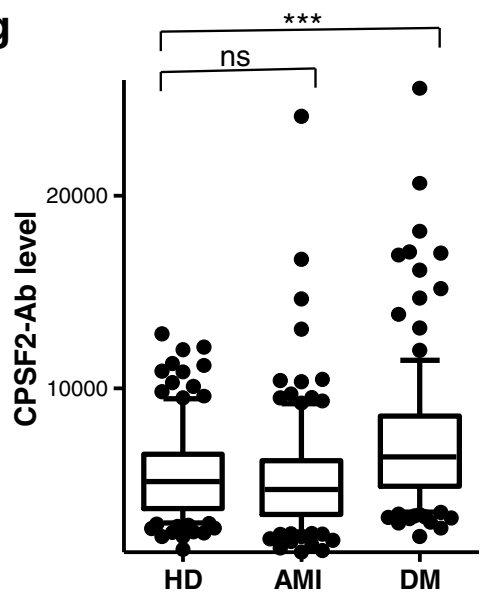

h

ROC: CPSF2 vS AMI

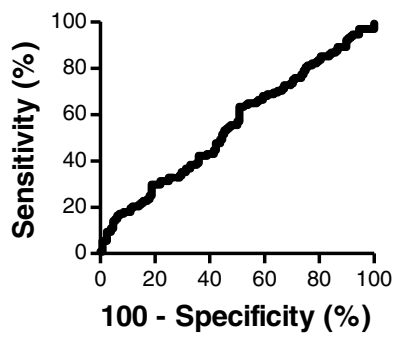

ROC: CPSF2 vs DM

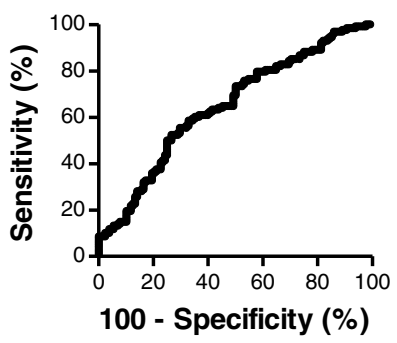

Fig. 3 Comparison of serum DIDO1-Abs, FOXJ2-Abs, and CPSF2-Abs levels between HDs and patients with acute myocardial infarction (AMI) and diabetes mellitus (DM). GST-DIDO1:1-275 (a), bFOXJ2-426 (d), and bCPSF2-607 (g) were used as antigens. Serum antibody levels in HDs and patients with AMI and type 2 DM were determined using AlphaLISA and are shown as box-whisker plots, as described in the legend of Fig. 2. The same results are summarized in Table 3. Responses to DIDO1-Abs (b, c), FOXJ2-Abs (e, f), and CPSF2-Abs (h, i) were also evaluated using ROC analysis, and summarized in Table 5

type 3 CKD were $7.3 \%, 43.4 \%, 37.5 \%$, and $26.8 \%$, respectively, and those of FOXJ2-Ab were 3.7\%, 28.3\%, 34.4\%, and $13.8 \%$, respectively (Table 4 ). No apparent difference was found in CPSF2-Ab levels between HDs and patients with any type of CKD (Fig. 4i, Table 4).

\section{ROC analysis}

The results of the ROC analysis are shown in Figs. 2b, c, e, f, h, i, 3b, c, e, f, h, i, 4b, c, d, f, g, h, j, k, l, S1B, and $\mathrm{S} 1 \mathrm{C}$ and summarized in Table 5 , in which the area under the curve (AUC), 95\% CI, cutoff value, sensitivity, specificity, and $P$ value are shown. Serum anti-DIDO1 antibody levels showed markedly high AUC values against CKD. The AUCs of DIDO1-Ab versus type 1, type 2 , and type 3 CKD were $0.8665,0.8728$, and 0.8227 , respectively. Thus, irrespective of the CKD type, DIDO1-Ab may discriminate kidney failure. The AUCs of DIDO1-Ab versus TIA and AIS were 0.6819 and 0.6476 , respectively, and similar values were observed for DIDO1pep-Ab (0.6503 and 0.6611, respectively). No significant increase above 0.6 was observed in AUCs of DIDO1-Ab versus AMI and DM. 
Table 2 Comparison of the serum antibody levels of HDs versus those of patients with transient ischemic attack (TIA) or acute ischemic stroke (AIS)

\begin{tabular}{|c|c|c|c|c|}
\hline \multicolumn{2}{|c|}{ Sample information } & $\mathrm{HD}$ & $\mathrm{TIA}$ & AIS \\
\hline & Total sample number & 285 & 92 & 464 \\
\hline & Male/female & 188/97 & $55 / 37$ & 271/193 \\
\hline & Age (average \pm SD) & $52.3 \pm 11.7$ & $70.2 \pm 11.6$ & $75.5 \pm 11.5$ \\
\hline \multicolumn{2}{|c|}{ Alpha analysis (antibody level) } & DIDO1-Ab & $\mathrm{FOXJ2-Ab}$ & CPSF2-Ab \\
\hline \multirow[t]{5}{*}{ HD } & Average & 4736 & 8568 & 2515 \\
\hline & SD & 3179 & 5103 & 1061 \\
\hline & Cutoff value & 11,095 & 18,774 & 4638 \\
\hline & Positive no. & 19 & 16 & 12 \\
\hline & Positive (\%) & $6.7 \%$ & $5.6 \%$ & $4.2 \%$ \\
\hline \multirow[t]{5}{*}{ TIA } & Average & 6950 & 12,390 & 3792 \\
\hline & SD & 5251 & 7533 & 4280 \\
\hline & Positive no. & 14 & 13 & 15 \\
\hline & Positive (\%) & $15.2 \%$ & $14.1 \%$ & $16.3 \%$ \\
\hline & $P$ (TIA vs HD) & 0.0002 & $<0.0001$ & 0.0056 \\
\hline \multirow[t]{5}{*}{ AIS } & Average & 7309 & 13,255 & 3291 \\
\hline & SD & 5415 & 8042 & 2396 \\
\hline & Positive no. & 81 & 91 & 69 \\
\hline & Positive (\%) & $17.5 \%$ & $19.6 \%$ & $14.9 \%$ \\
\hline & $P$ (AIS vs HD) & $<0.0001$ & $<0.0001$ & $<0.0001$ \\
\hline
\end{tabular}

The upper panel indicates the numbers of all samples and samples from males and females as well as the ages (average \pm SD). The lower panel summarizes the serum antibody levels (alpha luminescent photon count) examined by AlphaLISA. Purified DIDO1 (amino acids 1-275)-glutathione S-transferase (GST) protein and synthetic peptides, bFOXJ2-426 and bCPSF2-607, were used as antigens. The cutoff values were determined as the average $H D$ values plus two SDs, and positive samples for which the Alpha counts exceeded the cutoff value were scored. $P$ values were calculated using the Kruskal-Wallis test. $P$ values lower than 0.05 and positive rates higher than $10 \%$ are marked in bold. Box-whisker plots of the same results are shown in Fig. $2 \mathrm{a}, \mathrm{d}$, and $\mathrm{g}$

AUCs of FOXJ2-Ab were $>0.65$ versus TIA, AIS, AMI, DM, and CKD, among which AUC was the highest versus type 2 CKD (0.8769; Table 4). AUC versus DM was relatively low (0.6584). Thus, FOXJ2-Ab may be associated with kidney failure and atherosclerosis, but it does not primarily reflect DM. However, CPSF2-Ab was not associated with AMI or type 1/type 2/type 3 CKD. The lowest $P$ values were observed versus AIS and DM, suggesting that CPSF2-Abs reflect diabetic AIS.

Serum DIDO1-Ab, FOXJ2-Ab, and CPSF2-Ab levels in cancer Because autologous antibodies often develop in patients with cancer [11-14], we examined serum samples from patients with colorectal carcinoma, esophageal squamous cell carcinoma, gastric cancer, breast cancer, and pancreatic cancer obtained from Chiba University Hospital. Notably, serum DIDO1-Ab and CPSF2-Ab levels were not significantly different between HDs and patients with any type of cancer (Supplementary Table S1).
Table 3 Comparison of serum DIDO1-, FOXJ2-, and CPSF2-Ab levels between HDs and patients with acute myocardial infarction (AMI) or diabetes mellitus (DM) examined by AlphaLISA

\begin{tabular}{|c|c|c|c|c|}
\hline \multicolumn{2}{|c|}{ Alpha analysis (antibody level) } & \multirow{2}{*}{$\begin{array}{l}\text { DIDO1-Ab } \\
11,373\end{array}$} & \multirow{2}{*}{$\begin{array}{l}\text { FOXJ2-Ab } \\
12,218\end{array}$} & \multirow{2}{*}{$\begin{array}{l}\text { CPSF2-Ab } \\
5571\end{array}$} \\
\hline $\mathrm{HD}$ & Average & & & \\
\hline & SD & 1939 & 6636 & 2390 \\
\hline & Cutoff value & 15,251 & 25,490 & 10,351 \\
\hline & Positive no. & 4 & 4 & 7 \\
\hline & Positive (\%) & $3.1 \%$ & $3.1 \%$ & $5.5 \%$ \\
\hline \multirow[t]{5}{*}{ AMI } & Average & 11,634 & 22,965 & 5343 \\
\hline & SD & 2405 & 16,329 & 3070 \\
\hline & Positive no. & 10 & 44 & 6 \\
\hline & Positive (\%) & $7.8 \%$ & $34.4 \%$ & $4.7 \%$ \\
\hline & $P($ AMI vs HD) & 0.342 & $<0.0001$ & 0.508 \\
\hline \multirow[t]{5}{*}{ DM } & Average & 11,199 & 21,718 & 7232 \\
\hline & SD & 2252 & 24,383 & 3798 \\
\hline & Positive no. & 7 & 29 & 17 \\
\hline & Positive (\%) & $5.5 \%$ & $22.7 \%$ & $13.3 \%$ \\
\hline & $P$ (DM vs HD) & 0.508 & $<0.0001$ & $<0.0001$ \\
\hline
\end{tabular}

The antigens used were purified DIDO1-GST protein and synthetic peptides, bFOXJ2-426 and bCPSF2-607. The shown numbers are as described in Table 2; $P$ values lower than 0.05 and positive rates higher than $10 \%$ are marked in bold. Box-whisker plots of the same results are shown in Fig. 3a, d, and g

However, serum FOXJ2-Ab levels were significantly higher in patients with colorectal carcinoma but not in those with other types of cancer than in HDs.

\section{Association of serum DIDO1-Ab, FOXJ2-Ab, and CPSF2-Ab levels with autoimmune diseases}

Autoantibodies may have causal effects on autoimmune diseases such as Sjögren's syndrome, rheumatoid arthritis, SLE, and ulcerative colitis. Some of these autoimmunity-related characteristics are known to be involved in the development of atherosclerosis [61-64]. We examined antibody levels in serum samples from patients with Sjögren's syndrome, rheumatoid arthritis, SLE, and ulcerative colitis. Serum DIDO1-Ab and FOXJ2-Ab levels were significantly higher in patients with rheumatoid arthritis and SLE (but not in those with Sjögren's syndrome or ulcerative colitis) than in HDs (Supplementary Table S2). Serum CPSF2-Ab levels were higher in patients with rheumatoid arthritis (but not in those with Sjögren's syndrome, SLE, or ulcerative colitis) than in HDs.

\section{Association of serum DIDO1-Ab, FOXJ2-Ab, and CPSF2-Ab levels with pulmonary diseases}

OSA is frequently accompanied by hypertension. Serum anti-COPE was identified by SEREX screening using serum samples from patients with atherosclerosis, and 


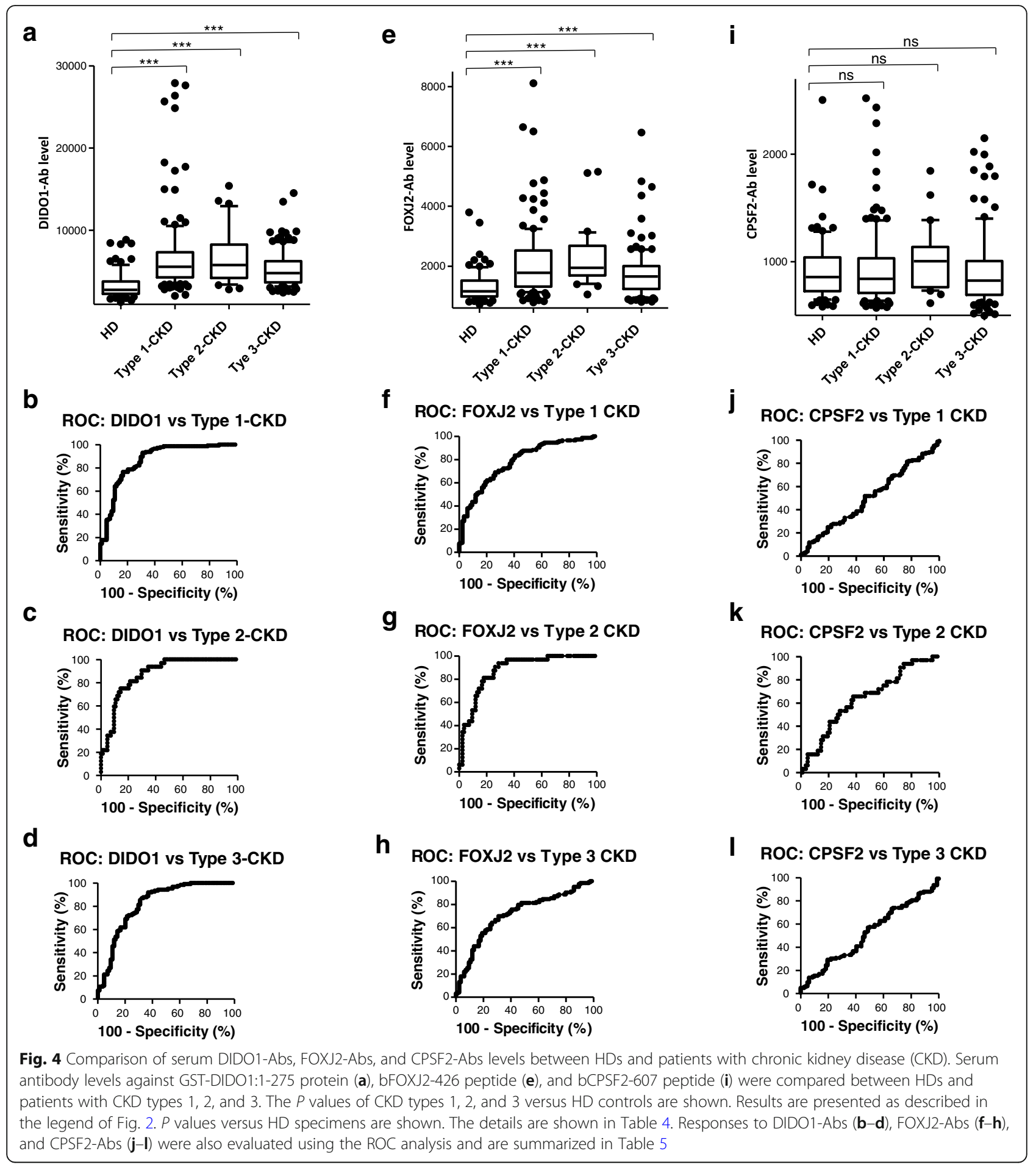

its level was elevated in patients with OSA compared with in HDs [65]. Pulmonary diseases including CTEPH and $\mathrm{PAH}$ are distinct from hypertension but could have an inflammatory condition similar to that in hypertension (e.g., elevation of Pentraxin 3 level) [66]. Serum FOXJ2-Ab levels were higher in patients with CTEPH and PAH (but not in those with OSA) than in HDs, whereas serum DIDO1-Ab and CPSF2-Ab levels did not show any apparent difference between HDs and patients with CTEPH, PAH, or OSA (Supplementary Table S3).

\section{Correlation analysis}

Comparative analysis of serum antibody levels and subject data was performed using 851 serum samples 
Table 4 Comparison of serum antibody levels of HDs versus those of patients with chronic kidney disease (CKD)

\begin{tabular}{|c|c|c|c|c|c|}
\hline \multicolumn{2}{|c|}{ Sample information } & $\mathrm{HD}$ & Type-1 CKD & Type-2 CKD & Type-3 CKD \\
\hline \multicolumn{2}{|c|}{ Total sample number } & 82 & 145 & 32 & 123 \\
\hline \multicolumn{2}{|c|}{ Male/female } & $44 / 38$ & $106 / 39$ & $21 / 11$ & $70 / 53$ \\
\hline \multicolumn{2}{|c|}{ Age (average \pm SD) } & $44.1 \pm 11.2$ & $66.0 \pm 10.4$ & $76.0 \pm 9.8$ & $62.0 \pm 11.7$ \\
\hline \multicolumn{2}{|c|}{ Alpha analysis (antibody level) } & DIDO1-Ab & FOXJ2-Ab & CPSF2-Ab & \\
\hline \multirow[t]{5}{*}{$\mathrm{HD}$} & Average & 3166 & 1300 & 914 & \\
\hline & SD & 1423 & 517 & 298 & \\
\hline & Cutoff value & 6012 & 2334 & 1509 & \\
\hline & Positive no. & 6 & 3 & 3 & \\
\hline & Positive rate (\%) & $7.3 \%$ & $3.7 \%$ & $3.7 \%$ & \\
\hline \multirow[t]{5}{*}{ Type 1-CKD } & Average & 6805 & 2141 & 939 & \\
\hline & SD & 4675 & 1330 & 382 & \\
\hline & Positive no. & 63 & 41 & 7 & \\
\hline & Positive rate (\%) & $43.4 \%$ & $28.3 \%$ & $4.8 \%$ & \\
\hline & $P($ vs HD) & $<0.0001$ & $<0.0001$ & 0.579 & \\
\hline \multirow[t]{5}{*}{ Type 2-CKD } & Average & 6693 & 2245 & 1020 & \\
\hline & SD & 3347 & 930 & 281 & \\
\hline & Positive no. & 12 & 11 & 2 & \\
\hline & Positive rate (\%) & $37.5 \%$ & $34.4 \%$ & $6.3 \%$ & \\
\hline & $P($ vs HD) & $<0.0001$ & $<0.0001$ & 0.081 & \\
\hline \multirow[t]{5}{*}{ Type 3-CKD } & Average & 5264 & 1770 & 936 & \\
\hline & SD & 2161 & 829 & 421 & \\
\hline & Positive no. & 33 & 17 & 10 & \\
\hline & Positive rate (\%) & $26.8 \%$ & $13.8 \%$ & $8.1 \%$ & \\
\hline & $P$ (vs HD) & $<0.0001$ & $<0.0001$ & 0.656 & \\
\hline
\end{tabular}

CKD types 1, 2, and 3 correspond to diabetic kidney disease, nephrosclerosis, and glomerulonephritis, respectively. The upper panel indicates the numbers of all samples and samples from males and females as well as age (average \pm SD). The lower panel summarizes the serum antibody levels examined by AlphaLISA using purified DIDO1-GST protein and synthetic bCPSF2 and bFOXJ2 peptides as antigens as described in the legend of Table 2. Box-whisker plots of the same results are shown in Fig. $4 a$, e, and i. $P$ values lower than 0.05 and positive rates higher than $10 \%$ are marked in bold

obtained from Chiba Prefectural Sawara Hospital including 188 serum samples from HDs, 162 from patients with DSWMH, 18 from patients with asympt-CI, 66 from patients with TIA, 351 from patients with AIS, 66 from patients with $\mathrm{cCI}$, and 66 from disease controls. Other subject information is shown in Supplementary Table S4. Comparison using Mann-Whitney $U$ test revealed that serum DIDO1pep-Ab, FOXJ2-Ab, and CPSF2-Ab levels were significantly higher in patients with TIA, AIS, and cCI (but not in those with DSWMH) than in HDs (Table 6, uppermost panel). Then, antibody levels were compared between males and females; those with or without DM, hypertension, CVD, and dyslipidemia; and those with or without smoking and alcohol intake habits. Hypertension was defined as a history of systolic blood pressure of $>140 \mathrm{mmHg}$, diastolic blood pressure of $>90 \mathrm{mmHg}$, or use of antihypertensive agents. Significantly higher serum DIDO1pep-Ab levels were observed in patients with hypertension, CVD, dyslipidemia, or a smoking habit (but not in those with DM) than in their control groups (Table 6, lower panels). Serum FOXJ2-Ab levels showed similar results, except that they were not correlated with dyslipidemia. Meanwhile, serum CPSF2-Ab levels were associated with $\mathrm{DM}$, hypertension, and smoking habit but not with CVD or dyslipidemia. Sex and alcohol intake displayed no association with any of these three antibody levels.

Spearman's rank-order correlation analysis was performed to determine the correlation between serum antibody levels of DIDO, FOXJ2, and CPSF2 peptides and subject parameters including general information such as age, body height, weight, body mass index, and degree of artery stenosis (maximum intima media thickness, max IMT). The following blood test data were also included: albumin/globulin ratio, aspartate aminotransferase, alanine amino transferase, alkaline phosphatase, lactate dehydrogenase, total bilirubin, cholinesterase, $\gamma$ glutamyl transpeptidase, total protein, albumin, blood 
Table 5 Receiver operating characteristic (ROC) analysis

\begin{tabular}{|c|c|c|c|c|}
\hline & DIDO1-Ab vs TIA & DIDO1-Ab vs AIS & & \\
\hline AUC & 0.6767 & 0.6023 & & \\
\hline $95 \% \mathrm{Cl}$ & $0.6001-0.7533$ & $0.5367-0.6680$ & & \\
\hline Cutoff value & 14,184 & 19,924 & & \\
\hline Sensitivity (\%) & $77.9 \%$ & $27.9 \%$ & & \\
\hline Specificity (\%) & $49.6 \%$ & $91.9 \%$ & & \\
\hline \multirow[t]{2}{*}{$P$ value } & $<0.0001$ & 0.0033 & & \\
\hline & DIDO1-Ab vs AMI & DIDO1-Ab vs DM & & \\
\hline AUC & 0.5163 & 0.5347 & & \\
\hline $95 \% \mathrm{Cl}$ & $0.4454-0.5875$ & $0.4638-0.6057$ & & \\
\hline Cutoff value & 13,519 & 10,700 & & \\
\hline Sensitivity (\%) & $22.7 \%$ & $46.9 \%$ & & \\
\hline Specificity (\%) & $85.8 \%$ & $63.8 \%$ & & \\
\hline \multirow[t]{2}{*}{$P$ value } & 0.650 & 0.338 & & \\
\hline & DIDO1-Ab vs type 1 CKD & DIDO1-Ab vs type 2 CKD & DIDO1-Ab vs type 3 CKD & \\
\hline AUC & 0.8665 & 0.8728 & 0.8227 & \\
\hline $95 \% \mathrm{Cl}$ & 0.8144 to 0.9186 & 0.8092 to 0.9364 & 0.7611 to 0.8843 & \\
\hline Cutoff value & 3375 & 3511 & 3158 & \\
\hline Sensitivity (\%) & $93.1 \%$ & $90.6 \%$ & $91.9 \%$ & \\
\hline Specificity (\%) & $69.1 \%$ & $70.2 \%$ & $63.1 \%$ & \\
\hline \multirow[t]{2}{*}{$P$ value } & $<0.0001$ & $<0.0001$ & $<0.0001$ & \\
\hline & DIDO1pep-Ab vs TIA & DIDO1pep-Ab vs AIS & & \\
\hline AUC & 0.6503 & 0.6611 & & \\
\hline $95 \% \mathrm{Cl}$ & $0.5751-0.7256$ & $0.6138-0.7084$ & & \\
\hline Cutoff value & 4662 & 8413 & & \\
\hline Sensitivity (\%) & $87.9 \%$ & $43.9 \%$ & & \\
\hline Specificity (\%) & $38.3 \%$ & $81.9 \%$ & & \\
\hline \multirow[t]{2}{*}{$P$ value } & 0.0003 & $<0.0001$ & & \\
\hline & FOXJ2-Ab vs TIA & FOXJ2-Ab vs AIS & CPSF2-Ab vs TIA & CPSF2-Ab vs AIS \\
\hline AUC & 0.6696 & 0.7006 & 0.6314 & 0.6369 \\
\hline $95 \% \mathrm{Cl}$ & 0.6066 to 0.7326 & 0.6626 to 0.7386 & $0.5631-0.6997$ & $0.5970-0.6768$ \\
\hline Cutoff value & 8978 & 8920 & 2643 & 2644 \\
\hline Sensitivity (\%) & $60.9 \%$ & $65.1 \%$ & $54.4 \%$ & $57.8 \%$ \\
\hline Specificity (\%) & $66.0 \%$ & $66.0 \%$ & $67.7 \%$ & $67.7 \%$ \\
\hline \multirow[t]{2}{*}{$P$ value } & $<0.0001$ & $<0.0001$ & 0.0002 & $<0.0001$ \\
\hline & FOXJ2-Ab vs AMI & FOXJ2-Ab vs DM & CPSF2-Ab vs AMI & CPSF2-Ab vs DM \\
\hline AUC & 0.7418 & 0.6584 & 0.5522 & 0.6464 \\
\hline $95 \% \mathrm{Cl}$ & 0.6813 to 0.8022 & 0.5922 to 0.7245 & 0.4817 to 0.6226 & 0.5792 to 0.7136 \\
\hline Cutoff value & 14,437 & 20,978 & 5356 & 6145 \\
\hline Sensitivity (\%) & $68.0 \%$ & $34.4 \%$ & $63.3 \%$ & $55.5 \%$ \\
\hline Specificity (\%) & $71.1 \%$ & $91.4 \%$ & $49.2 \%$ & $70.3 \%$ \\
\hline$P$ value & $<0.0001$ & $<0.0001$ & 0.149 & $<0.0001$ \\
\hline
\end{tabular}


Table 5 Receiver operating characteristic (ROC) analysis (Continued)

\begin{tabular}{llll}
\hline & FOXJ2-Ab vs type 1 CKD & FOXJ2-Ab vs type 2 CKD & FOXJ2-Ab vs type 3 CKD \\
AUC & $\mathbf{0 . 7 8 1 2}$ & $\mathbf{0 . 8 7 6 9}$ & $\mathbf{0 . 7 1 5 1}$ \\
$95 \%$ Cl & 0.7200 to 0.8424 & 0.8124 to 0.9413 & 0.6439 to 0.7862 \\
Cutoff value & 1236 & 1391 & 1354 \\
Sensitivity (\%) & $83.5 \%$ & $93.8 \%$ & $69.9 \%$ \\
Specificity (\%) & $59.5 \%$ & $71.4 \%$ & $69.1 \%$ \\
P value & $<\mathbf{0 . 0 0 0 1}$ & $<\mathbf{0 . 0 0 0 1}$ & $<\mathbf{0 . 0 0 0 1}$ \\
& & & \\
AUC & CPSF2-Ab vs Type-1 CKD & CPSF2-Ab vsType-2 CKD & CPSF2-Ab vsType-3 CKD \\
95\% Cl & 0.5040 & 0.6387 & 0.5196 \\
Cutoff value & $0.4262-0.5817$ & $0.5274-0.7500$ & $0.4395-0.5996$ \\
Sensitivity (\%) & 641.5 & 901 & 706 \\
Specificity (\%) & $11.7 \%$ & $65.6 \%$ & $29.3 \%$ \\
$P$ value & $93.9 \%$ & $62.2 \%$ & $80.5 \%$ \\
\hline
\end{tabular}

Area under the curve (AUC), $95 \% \mathrm{Cl}$, cutoff value, sensitivity (\%), specificity (\%), and $P$ value of the ROC analysis are shown. Purified GST-DIDO1 protein and synthetic peptides-bDIDO1-297 (DIDO1 pep), bFOXJ2-426, and bCPSF2-607-were used as antigens. $P$ values lower than 0.05 and AUCs higher than 0.7 are marked in bold

urea nitrogen, creatinine, estimated glomerular filtration rate, uric acid, amylase, total cholesterol, high-density lipoprotein cholesterol, triglyceride, sodium, potassium, chlorine, calcium, inorganic phosphate, iron, C-reactive protein, low-density lipoprotein cholesterol, white blood cells, red blood cells, hemoglobin, hematocrit, mean corpuscular volume, mean corpuscular hemoglobin, mean corpuscular hemoglobin concentration, red cell distribution width, platelets, mean platelet volume, procalcitonin, platelet distribution width, blood sugar, and glycated hemoglobin (HbA1c).

All three antibody levels were correlated with age and max IMT but inversely correlated with height and weight and cholinesterase, total protein, and albumin levels. Serum DIDO1 and FOXJ2 antibody levels, but not serum CPSF2 antibody level, were correlated with alkaline phosphatase, white blood cell count, and mean corpuscular volume (Table 7). Blood sugar and HbA1c, which reflect DM, were not correlated with these antibody levels, except for a slight correlation $(P=0.195)$ between serum DIDO1pep-Ab level and blood sugar.

\section{Immunohistochemical analysis of antigenic proteins}

Assuming that autoantibodies against DIDO1, FOXJ2, and CPSF2 peptides develop in patients with atherosclerotic diseases, these antigenic proteins should be expressed at high levels in atherosclerotic lesions. As such, we also examined the expressions of antigenic proteins in surgically resected carotid atherosclerotic plaques via immunohistochemistry. The DIDO1 and CPSF2 proteins were predominantly expressed in the intima of atherosclerotic plaques, similar to the localization of vimentin and smooth muscle actin, which are markers for smooth muscle cells (Fig. 5). DHPS, reported as an atherosclerosis marker [55], was also expressed in smooth muscle cells. The expression of FOXJ2 showed a similar pattern as that of CD31- and CD34positive vascular endothelial cells. CD68 expression in macrophages was not similar to any of the other antigen expressions (Fig. 5).

\section{JPHC cohort analysis}

We conducted a case-control study nested within the JPHC-based Prospective Study, which involved approximately 30,000 plasma samples [52, 53]. The antibody level against the DIDO1 protein was positively and strongly associated with a risk of AIS: odds ratios (95\% CIs) were 3.99 (1.93-8.23), 3.40 (1.62-7.13), and 4.02 (1.94-8.35) for those with the second, third, and highest quartiles of antibody levels, respectively, versus for those with the lowest quartile (Table 8). Likewise, the antibody levels of the DIDO1, FOXJ2, and CPSF2 peptides were positively correlated with a risk of cerebral infarction: odds ratios (95\% CIs) of the highest quartile were 2.66 (1.43-4.95), 2.24 (1.27-3.95), and 2.41 (1.33-4.37), respectively. These results indicate that the antibody markers against the DIDO1 protein and DIDO1, FOXJ2, and CPSF2 peptides are useful in predicting the onset of AIS.

\section{Discussion}

Three novel antibody markers for atherosclerosis

We performed large-scale screening using SEREX and the protein microarray method and identified 69 candidate antigenic proteins related to atherosclerosis (Table $1)$. In the present study, we focused on three antigensDIDO1, FOXJ2, and CPSF2-that appeared to be of 
Table 6 Correlation analysis of antibody levels against synthetic bDIDO1, bCPSF2, and bFOXJ2 peptides with data of subjects in the Sawara Hospital cohort

\begin{tabular}{|c|c|c|c|c|c|c|c|}
\hline Present disease & & $\mathrm{HD}$ & DSWMH & asympt-Cl & $\mathrm{TIA}$ & AIS & $\mathrm{cCl}$ \\
\hline Sample number & & 188 & 162 & 18 & 66 & 351 & 66 \\
\hline \multirow[t]{2}{*}{ DIDO1pep-Ab level } & Average & 3381 & 3523 & 3481 & 4443 & 4688 & 4347 \\
\hline & SD & 1660 & 1750 & 2099 & 2576 & 2740 & 3017 \\
\hline$P$ value (vs HD) & & - & ns & ns & $<0.01$ & $<0.001$ & $<0.05$ \\
\hline \multirow[t]{2}{*}{ FOXJ2-Ab level } & Average & 4627 & 4995 & 4902 & 5794 & 6298 & 7022 \\
\hline & SD & 1972 & 2232 & 1854 & 2368 & 3308 & 5646 \\
\hline$P$ value (vs HD) & & - & ns & ns & $<0.01$ & $<0.001$ & $<0.001$ \\
\hline \multirow[t]{2}{*}{ CPSF2-Ab level } & Average & 7322 & 7571 & 8312 & 11,778 & 8722 & 10,088 \\
\hline & SD & 3415 & 2942 & 2461 & 16,843 & 3970 & 4240 \\
\hline$P$ value (vs HD) & & - & ns & $<0.05$ & $<0.01$ & $<0.001$ & $<0.001$ \\
\hline Sex & & Male & Female & & & & \\
\hline Sample number & & 528 & 389 & & & & \\
\hline \multirow[t]{2}{*}{ DIDO1pep-Ab level } & Average & 4081 & 4038 & & & & \\
\hline & SD & 2493 & 2244 & & & & \\
\hline$P$ value (vs Male) & & & 0.781 & & & & \\
\hline \multirow[t]{2}{*}{ FOXJ2-Ab level } & Average & 5772 & 5443 & & & & \\
\hline & SD & 3077 & 3084 & & & & \\
\hline$P$ value (vs male) & & & 0.111 & & & & \\
\hline \multirow[t]{2}{*}{ CPSF2-Ab level } & Average & 8633 & 8420 & & & & \\
\hline & SD & 5493 & 6553 & & & & \\
\hline$P$ value (vs male) & & & 0.155 & & & & \\
\hline Complication & & $\mathrm{DM}-$ & $\mathrm{DM}+$ & & & & \\
\hline Sample number & & 732 & 180 & & & & \\
\hline \multirow[t]{2}{*}{ DIDO1pep-Ab level } & Average & 4059 & 4047 & & & & \\
\hline & SD & 2469 & 2027 & & & & \\
\hline$P$ value (vs DM-) & & & 0.949 & & & & \\
\hline \multirow[t]{2}{*}{ FOXJ2-Ab level } & Average & 5589 & 5763 & & & & \\
\hline & SD & 3104 & 2987 & & & & \\
\hline$P$ value (vs DM-) & & & 0.488 & & & & \\
\hline \multirow[t]{2}{*}{ CPSF2-Ab level } & Average & 8319 & 9437 & & & & \\
\hline & SD & 5373 & 7822 & & & & \\
\hline$P$ value (vs DM-) & & & 0.015 & & & & \\
\hline Complication & & HT- & $\mathrm{HT}+$ & & & & \\
\hline Sample number & & 347 & 565 & & & & \\
\hline \multirow[t]{2}{*}{ DIDO1pep-Ab level } & Average & 3830 & 4196 & & & & \\
\hline & SD & 2217 & 2477 & & & & \\
\hline$P$ value (vs HT-) & & & 0.021 & & & & \\
\hline \multirow[t]{2}{*}{ FOXJ2-Ab level } & Average & 5093 & 5948 & & & & \\
\hline & SD & 2373 & 3405 & & & & \\
\hline$P$ value (vs HT-) & & & $<0.0001$ & & & & \\
\hline \multirow[t]{2}{*}{ CPSF2-Ab level } & Average & 7699 & 9065 & & & & \\
\hline & SD & 6095 & 5804 & & & & \\
\hline$P$ value (vs HT-) & & & $<0.0001$ & & & & \\
\hline
\end{tabular}


Table 6 Correlation analysis of antibody levels against synthetic bDIDO1, bCPSF2, and bFOXJ2 peptides with data of subjects in the Sawara Hospital cohort (Continued)

\begin{tabular}{|c|c|c|c|}
\hline Complication & & CVD- & CVD+ \\
\hline Sample number & & 861 & 51 \\
\hline \multirow[t]{2}{*}{ DIDO1pep-Ab level } & Average & 4003 & 4966 \\
\hline & SD & 2360 & 2673 \\
\hline$P$ value (vs CVD-) & & & 0.015 \\
\hline \multirow[t]{2}{*}{ FOXJ2-Ab level } & Average & 5559 & 6712 \\
\hline & SD & 3050 & 3408 \\
\hline$P$ value (vs CVD-) & & & 0.022 \\
\hline \multirow[t]{2}{*}{ CPSF2-Ab level } & Average & 8499 & 9232 \\
\hline & SD & 6037 & 4239 \\
\hline$P$ value (vs CVD-) & & & 0.142 \\
\hline Complication & & Lipidemia- & Lipidemia+ \\
\hline Sample number & & 649 & 263 \\
\hline \multirow[t]{2}{*}{ DIDO1pep-Ab level } & Average & 4158 & 3806 \\
\hline & SD & 2497 & 2073 \\
\hline$P$ value (vs Lipidemia-) & & & 0.029 \\
\hline \multirow[t]{2}{*}{ FOXJ2-Ab level } & Average & 5702 & 5428 \\
\hline & SD & 3171 & 2841 \\
\hline$P$ value (vs Lipidemia-) & & & 0.203 \\
\hline \multirow[t]{2}{*}{ CPSF2-Ab level } & Average & 8146 & 9531 \\
\hline & SD & 3583 & 9534 \\
\hline$P$ value (vs Lipidemia-) & & & 0.145 \\
\hline Lifestyle & & Non-smoker & Smoker \\
\hline Sample number & & 474 & 441 \\
\hline \multirow[t]{2}{*}{ DIDO1pep-Ab level } & Average & 3732 & 4425 \\
\hline & SD & 2037 & 2676 \\
\hline$P$ value (vs non-smoker) & & & $<0.0001$ \\
\hline \multirow[t]{2}{*}{ FOXJ2-Ab level } & Average & 5192 & 6111 \\
\hline & SD & 2793 & 3309 \\
\hline$P$ value (vs non-smoker) & & & $<0.0001$ \\
\hline \multirow[t]{2}{*}{ CPSF2-Ab level } & Average & 8214 & 8901 \\
\hline & SD & 6086 & 5801 \\
\hline$P$ value (vs non-smoker) & & & 0.002 \\
\hline Lifestyle & & Alcohol- & Alcohol+ \\
\hline Sample number & & 334 & 581 \\
\hline \multirow[t]{2}{*}{ DIDO1pep-Ab level } & Average & 4001 & 4103 \\
\hline & SD & 2236 & 2476 \\
\hline$P$ value (vs Alcohol-) & & & 0.527 \\
\hline \multirow[t]{2}{*}{ FOXJ2-Ab level } & Average & 5691 & 5603 \\
\hline & SD & 3542 & 2793 \\
\hline$P$ value (vs Alcohol-) & & & 0.698 \\
\hline \multirow[t]{2}{*}{ CPSF2-Ab level } & Average & 8559 & 8591 \\
\hline & SD & 6946 & 5341 \\
\hline$P$ value (vs Alcohol-) & & & 0.361 \\
\hline
\end{tabular}

The subjects were divided as follows: sex (male and female); presence (+) or absence (-) of complication of DM, hypertension (HT), cardiovascular disease (CVD), or dyslipidemia, and lifestyle factors (smoking and alcohol intake habits). Antibody levels (Alpha counts) were compared using the Kruskal-Wallis test (upper panel) and the Mann-Whitney $U$ test (lower panels). Sample numbers, averages, and SDs of counts as well as $P$ values are shown. Significant correlations $(P<0.05)$ are marked in bold 
much interest in relation to AIS. The presence of antibodies against these proteins was confirmed by Western blotting (Fig. 1). We then examined epitopes and selected bDIDO1-297, bFOXJ2-426, and bCPSF2-607 as useful antigenic peptides to measure serum antibody levels. The amino-terminal half of DIDO1 was also used as an antigen. Serum antibody levels of these antigens were more elevated in patients with AIS and TIA than in HDs (Fig. 2, Supplementary Figure S1). All of bDIDO1-297, bFOXJ2-426, and bCPSF2-607 were closely correlated with max IMT (Table 7), which is a typical index of the development of atherosclerosis leading to AIS and CVD [67-70]. Thus, these serum antibodies can be markers for atherosclerosis. A casecontrol study nested within the JPHC-based Prospective Study showed that the three antibody markers are associated with the risk of cerebral infarction and indicated that these markers are useful in predicting the onset of cerebral infarction (Table 8). However, they had distinct characteristics.

The DIDO1 protein was first identified as a regulator of apoptosis [71]. Serum DIDO1pep-Ab levels were elevated in patients with TIA, AIS, CCI, CKD, rheumatoid arthritis, and SLE but not in those with AMI, DM, any type of cancer, or ulcerative colitis (Figs. 2, 3, and 4; Tables 2, 3 and 4; Supplementary Tables S2 and S3). In particular, the AUC values of DIDO1 versus CKD were $>0.8$ (Table 5), suggesting that DIDO1-Ab reflects kidney failure basically and atherosclerosis indirectly.

FOXJ2 is a member of the forkhead family of transcription factors [72]. Serum FOXJ2-Ab levels were elevated in patients with TIA, AIS, cCI, AMI, DM, CKD, colorectal carcinoma, rheumatoid arthritis, and SLE compared with in HDs (Figs. 2, 3, and 4; Tables 2, 3, and 4; Supplementary Tables S1 and S2). Serum FOXJ2-Ab levels correlated well with hypertension (Table 6) and were elevated in patients with CTEPH and PAH (Supplementary Table S3), suggesting that these levels reflect systemic arterial hypertension and can differentiate hypertension-related diseases. In fact, hypertension is also a risk factor for colorectal carcinoma [73], and SLE is frequently associated with PAH [74].

Collagen diseases such as rheumatoid arthritis and SLE are high-risk groups of AIS and AMI [61, 62]. Serum DIDO1-Ab and FOXJ2-Ab levels were significantly associated with rheumatoid arthritis and SLE but not with Sjögren's syndrome or ulcerative colitis (Supplementary Table $\mathrm{S} 2$ ). It is possible that DIDO1-Ab and FOXJ2-Ab are discriminant in the case of AIS of which one of the causes is a collagen disease. That is, each marker may correspond to a different cause of atherosclerosis.

CPSF2 encodes the 100-kD subunit of CPSF, which plays a central role in the $3^{\prime}$ processing of pre-mRNA [75]. Serum CPSF2-Ab levels were associated primarily with AIS and DM and partly with TIA, cCI, esophageal squamous cell carcinoma, and rheumatoid arthritis but not with AMI, CKD, CVD, colorectal carcinoma, gastric cancer, breast cancer, pancreatic cancer, Sjögren's syndrome, SLE, or ulcerative colitis (Figs. 2, 3, 4; Tables 2, 3, and 4; Supplementary Tables S1 and S2). Serum CPSF2-Ab levels were correlated with aortic hypertension (Table 6) but not with pulmonary hypertension such as CTEPH and $\mathrm{PAH}$ (Supplementary Table S3). Moreover, the levels correlated most closely with max IMT (Table 7), indicating that CPSF2-Ab can mainly detect DM-caused atherosclerosis leading to AIS.

\section{Relationship between BMP/TGF- $\beta$ and atherosclerosis}

Bone morphogenetic proteins (BMPs) are involved in the transforming growth factor- $\beta$ (TGF- $\beta$ ) superfamily. It is well documented that BMP signals play important roles in the development of atherosclerosis [76, 77]. BMP-2 and BMP-4 expressions were elevated in atherosclerotic endothelium [78, 79], and plasma BMP-2 levels are elevated in patients with type $2 \mathrm{DM}$ [80]. Chronic infusion of BMP-4 induces endothelial dysfunction and hypertension [81], and treatment with the BMP antagonist, matrix Gla protein, and BMP inhibitors prevents the development of ATS [82, 83]. On the other hand, the knockdown of the BMP type II receptor BMPRII accelerates ATS [84]. Therefore, BMP family members may play a subtle regulatory role in the development of ATS. It should be noted that DIDO1 is the target gene of BMP and promotes cell attachment, migration, invasion, and apoptosis resistance in melanoma [85].

CPSF proteins interact with Smad via Smicl and potentiate TGF- $\beta / B M P$-stimulated Smad-dependent transcriptional responses $[86,87]$. We previously reported the elevation of autoantibodies against SOSTDC1 and NBL1/ DAN, which are the antagonists of BMP, in patients with AIS [48] and OSA [36], respectively. As such, it is possible that some, if not all, autoantibodies against TGF- $\beta /$ BMPrelated proteins play causal or suppressive roles in the development of atherosclerosis-related diseases.

\section{Involvement of marker genes in development and differentiation}

DIDO1 is the target gene of Oct4, Sox2, and Nanog; in reverse, Nanog and Oct4 are the target genes of DIDO1 [88]. Thus, DIDO1 plays a key role in the self-renewal of embryonic stem cells. Futterer suggested that DIDO1 is a switchboard that regulates embryonic stem cell transition from pluripotency maintenance to differentiation [89]. During the development of atherosclerosis, smooth muscle cells differentiate into foam cells to form atheroma [90]. Highly expressed DIDO1 in intimal smooth muscle cells (Fig. 5) may have an important role in their differentiation into foam cells. 
Table 7 Correlation analysis of serum antibody levels against synthetic bDIDO1, bCPSF2, and bFOXJ2 peptides with data on subjects in the Sawara Hospital cohort

\begin{tabular}{|c|c|c|c|c|c|c|c|}
\hline \multirow[t]{2}{*}{ Parameter* } & \multirow{2}{*}{$\begin{array}{l}\text { Number } \\
\text { of } X Y \\
\text { pairs }\end{array}$} & \multicolumn{2}{|c|}{ DID01pep-Ab } & \multicolumn{2}{|c|}{ FOXJ2pep-Ab } & \multicolumn{2}{|c|}{ CPSF2pep-Ab } \\
\hline & & $r$ value ${ }^{* *}$ & $P$ value & $r$ value & $P$ value & $r$ value & $P$ value \\
\hline Age & 851 & 0.2074 & $<0.0001^{* * *}$ & 0.2688 & $<0.0001$ & 0.1657 & $<0.0001$ \\
\hline Height & 844 & -0.1227 & 0.0004 & -0.1229 & 0.0003 & -0.0799 & 0.0202 \\
\hline Weight & 848 & -0.1047 & 0.0023 & -0.1196 & 0.0005 & -0.0707 & 0.0396 \\
\hline $\mathrm{BMI}$ & 843 & -0.0311 & 0.3679 & -0.0552 & 0.1098 & -0.0343 & 0.3197 \\
\hline $\max$ IMT & 646 & 0.1908 & $<0.0001$ & 0.2717 & $<0.0001$ & 0.2161 & $<0.0001$ \\
\hline $\mathrm{A} / \mathrm{G}$ & 820 & -0.0303 & 0.3858 & -0.0484 & 0.1662 & -0.0906 & 0.0094 \\
\hline AST & 848 & 0.0605 & 0.0782 & 0.0205 & 0.5523 & -0.0496 & 0.1490 \\
\hline $\mathrm{ALT}$ & 847 & 0.0063 & 0.8545 & -0.0079 & 0.8177 & -0.0800 & 0.0199 \\
\hline ALP & 786 & 0.0850 & 0.0172 & 0.0743 & 0.0374 & 0.0319 & 0.3716 \\
\hline $\mathrm{LDH}$ & 822 & 0.0718 & 0.0395 & 0.0291 & 0.4046 & -0.0134 & 0.7017 \\
\hline tBil & 830 & -0.0576 & 0.0972 & -0.0752 & 0.0304 & -0.1024 & 0.0031 \\
\hline $\mathrm{CHE}$ & 646 & -0.0895 & 0.0230 & -0.1671 & $<0.0001$ & -0.0982 & 0.0125 \\
\hline$\gamma$-GTP & 795 & 0.0334 & 0.3474 & 0.0240 & 0.4996 & -0.0028 & 0.9381 \\
\hline TP & 823 & -0.0971 & 0.0053 & -0.1443 & $<0.0001$ & -0.1084 & 0.0018 \\
\hline Albumin & 832 & -0.0757 & 0.0289 & -0.1294 & 0.0002 & -0.1358 & $<0.0001$ \\
\hline BUN & 846 & 0.0179 & 0.6038 & 0.0431 & 0.2103 & -0.0381 & 0.2686 \\
\hline CRE & 842 & -0.0090 & 0.7946 & 0.0472 & 0.1714 & -0.0341 & 0.3233 \\
\hline eGFR & 758 & 0.0176 & 0.6284 & -0.0255 & 0.4835 & 0.0230 & 0.5282 \\
\hline UA & 622 & 0.0336 & 0.4023 & 0.0255 & 0.5261 & 0.0050 & 0.9006 \\
\hline AMY & 527 & -0.0780 & 0.0735 & -0.0422 & 0.3350 & -0.0391 & 0.3701 \\
\hline $\mathrm{T}-\mathrm{CHO}$ & 744 & -0.0520 & 0.1568 & -0.0604 & 0.0994 & -0.1207 & 0.0010 \\
\hline $\mathrm{HDL}-\mathrm{C}$ & 550 & -0.0458 & 0.2840 & -0.0521 & 0.2222 & 0.0553 & 0.1952 \\
\hline $\mathrm{TG}$ & 589 & 0.0199 & 0.6303 & 0.0038 & 0.9274 & -0.0405 & 0.3261 \\
\hline $\mathrm{Na}$ & 833 & 0.0200 & 0.5635 & 0.0233 & 0.5027 & 0.0005 & 0.9881 \\
\hline K & 832 & -0.0275 & 0.4280 & -0.0091 & 0.7928 & -0.0072 & 0.8359 \\
\hline $\mathrm{Cl}$ & 833 & 0.0056 & 0.8708 & 0.0470 & 0.1752 & 0.0269 & 0.4376 \\
\hline $\mathrm{Ca}$ & 495 & -0.0210 & 0.6408 & -0.0815 & 0.0708 & -0.0405 & 0.3682 \\
\hline IP & 388 & -0.0023 & 0.9639 & -0.0465 & 0.3618 & 0.0546 & 0.2836 \\
\hline $\mathrm{Fe}$ & 400 & -0.0406 & 0.4185 & -0.0575 & 0.2526 & -0.0472 & 0.3465 \\
\hline CRP & 617 & 0.1172 & 0.0035 & 0.0775 & 0.0552 & 0.1041 & 0.0096 \\
\hline LDL-C & 440 & -0.0513 & 0.2831 & -0.0771 & 0.1071 & -0.1180 & 0.0133 \\
\hline WBC & 846 & 0.1036 & 0.0026 & 0.0848 & 0.0138 & 0.0417 & 0.2262 \\
\hline $\mathrm{RBC}$ & 846 & -0.0426 & 0.2155 & -0.0649 & 0.0596 & -0.0711 & 0.0386 \\
\hline $\mathrm{HGB}$ & 846 & -0.0113 & 0.7420 & -0.0329 & 0.3406 & -0.0672 & 0.0508 \\
\hline $\mathrm{HCT}$ & 846 & -0.0078 & 0.8214 & -0.0271 & 0.4317 & -0.0528 & 0.1249 \\
\hline MCV & 846 & 0.0683 & 0.0472 & 0.0959 & 0.0053 & 0.0510 & 0.1387 \\
\hline $\mathrm{MCH}$ & 846 & 0.0474 & 0.1681 & 0.0776 & 0.0242 & 0.0081 & 0.8136 \\
\hline $\mathrm{MCHC}$ & 846 & -0.0149 & 0.6659 & -0.0253 & 0.4635 & -0.0617 & 0.0728 \\
\hline RDW & 846 & 0.0489 & 0.1551 & 0.0449 & 0.1928 & 0.0529 & 0.1245 \\
\hline PLT & 846 & -0.0047 & 0.8919 & -0.0443 & 0.1992 & 0.0128 & 0.7097 \\
\hline MPV & 846 & -0.0201 & 0.5589 & -0.0637 & 0.0646 & -0.0012 & 0.9716 \\
\hline PCT & 846 & -0.0030 & 0.9312 & -0.0568 & 0.0993 & 0.0188 & 0.5853 \\
\hline
\end{tabular}


Table 7 Correlation analysis of serum antibody levels against synthetic bDIDO1, bCPSF2, and bFOXJ2 peptides with data on subjects in the Sawara Hospital cohort (Continued)

\begin{tabular}{|c|c|c|c|c|c|c|c|}
\hline \multirow[t]{2}{*}{ Parameter* } & \multirow{2}{*}{$\begin{array}{l}\text { Number } \\
\text { of } X Y \\
\text { pairs }\end{array}$} & \multicolumn{2}{|c|}{ DID01pep-Ab } & \multicolumn{2}{|c|}{ FOXJ2pep-Ab } & \multicolumn{2}{|c|}{ CPSF2pep-Ab } \\
\hline & & $r$ value ${ }^{* *}$ & $P$ value & $r$ value & $P$ value & $r$ value & $P$ value \\
\hline PDW & 846 & -0.0151 & 0.6611 & -0.0587 & 0.0886 & -0.0109 & 0.7512 \\
\hline BS & 783 & 0.0834 & 0.0195 & 0.0678 & 0.0581 & 0.0644 & 0.0718 \\
\hline $\mathrm{HbA1c}$ & 655 & -0.0204 & 0.6031 & -0.0170 & 0.6644 & -0.0277 & 0.4789 \\
\hline
\end{tabular}

*Subjects' data used were age, height, weight, body mass index (BMI), maximum intima-media thickness (max IMT), albumin/globulin ratio (A/G), aspartate aminotransferase (AST), alanine amino transferase (ALT), alkaline phosphatase (ALP), lactate dehydrogenase (LDH), total bilirubin (tBil), cholinesterase (CHE), $\gamma^{-}$ glutamyl transpeptidase ( $\gamma$-GTP), total protein (TP), albumin, blood urea nitrogen (BUN), creatinine (CRE), estimated glomerular filtration rate (eGFR), uric acid (UA), amylase (AMY), total cholesterol (T-CHO), high-density lipoprotein cholesterol (HDL-C), triglyceride (TG), sodium (Na), potassium (K), chlorine (Cl), calcium (Ca), inorganic phosphate (IP), iron (Fe), C-reactive protein (CRP), low-density lipoprotein cholesterol (LDL-C), white blood cells (WBC), red blood cells (RBC), hemoglobin $(\mathrm{HGB})$, hematocrit $(\mathrm{HCT})$, mean corpuscular volume (MCV), mean corpuscular hemoglobin $(\mathrm{MCH})$, $\mathrm{MCH}$ concentration (MCHC), red cell distribution width (RDW), platelets (PLT), mean platelet volume (MPV), procalcitonin (PCT), platelet distribution width (PDW), blood sugar (BS), and glycated hemoglobin (HbA1c) ${ }^{* *}$ Correlation coefficients ( $r$ values) and $P$ values obtained through Spearman's correlation analysis are shown

***Significant correlations $(P<0.05)$ are marked in bold

FOXJ2 expression is also regulated by Oct4 and involved in oocyte development [91]. Transient FOXJ2 transgenesis experiments have shown that FOXJ2 overexpression has a lethal effect on embryonic development from E10.5 [92]. FOXJ2 is also involved in differentiation and inhibits TGF- $\beta 1$-induced epithelial-mesenchymal transition [93]. Thus, high FOXJ2 expression (Fig. 5) may affect otherwise normally functioning vascular endothelial cells.

\section{Relationship between atherosclerosis and cancer}

BMP-induced DIDO1 promotes cell attachment, migration, invasion, and apoptosis resistance in melanoma [85]. Serum FOXJ2-Ab levels, which correlated well with hypertension, were elevated in patients with colorectal carcinoma $(P<0.001)$ but not in those with esophageal squamous cell carcinoma, gastric cancer, breast cancer, or pancreatic cancer (Supplementary Table S1). This is consistent with the report that hypertension is also a risk

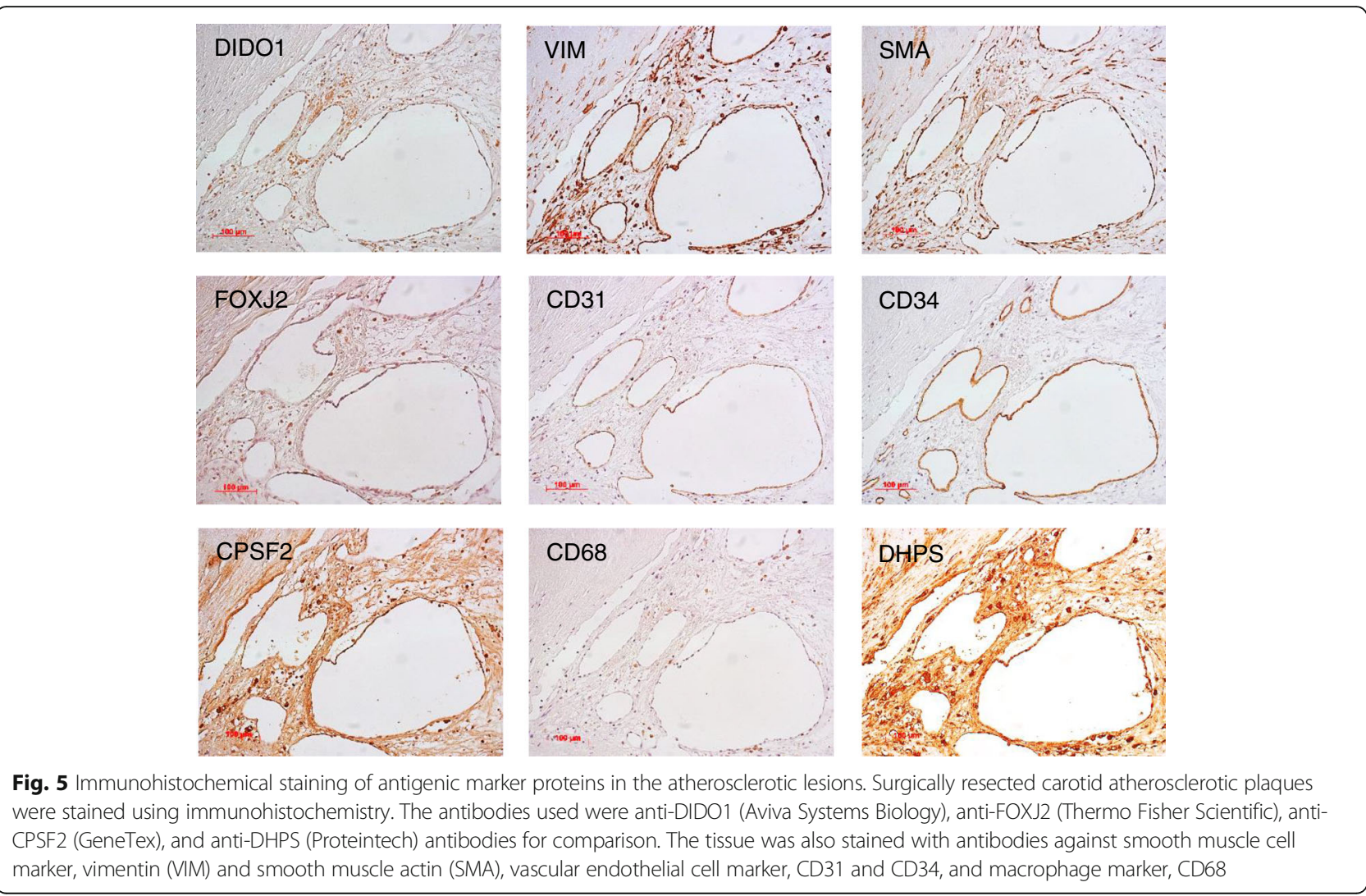


Table 8 Results of the Japan Public Health Center (JPHC) cohort samples

\begin{tabular}{llllll}
\hline & & DIDO1-Ab vs AIS & DIDO1pep-Ab vs AIS & FOXJ2-Ab vs AIS & CPSF2-Ab vs AIS \\
\hline 2nd & Matched OR & 3.99 & 1.92 & 1.43 & 1.19 \\
& $95 \% \mathrm{Cl}$ & $1.93-8.23$ & $1.03-3.58$ & $0.78-2.62$ & $0.63-2.23$ \\
3rd & Matched OR & 3.40 & 2.40 & 1.32 & 1.66 \\
& $95 \% \mathrm{Cl}$ & $1.62-7.13$ & $1.29-4.46$ & $0.72-2.43$ & $0.89-3.09$ \\
Max & Matched OR & 4.02 & 2.66 & 2.24 & 2.41 \\
& $95 \% \mathrm{Cl}$ & $1.94-8.35$ & $1.43-4.95$ & $1.27-3.95$ & $1.33-4.37$ \\
\hline
\end{tabular}

The odds ratios (ORs) and $95 \% \mathrm{Cl}$ of the $2 \mathrm{nd}$, 3rd, and the highest (max) quartiles versus the lowest quartile are shown for AIS with respect to the antibody levels of DIDO1 protein, DIDO1 peptide, FOXJ2 peptide, and CPSF2 peptide

factor for colorectal carcinoma but not for esophageal squamous cell carcinoma or gastric cancer [73, 94].

FOXJ2 overexpression is associated with poor prognosis, progression, and metastasis in nasopharyngeal carcinoma [95]. FOXQ1, a member of the FOX family, is overexpressed in colorectal cancer, and it enhances tumorigenicity and tumor growth [96]. However, it has been reported that FOXJ2 suppresses migration and invasion in extrahepatic cholangiocarcinoma [97], hepatocellular carcinoma [98], glioma [99], and breast cancer [100]. Thus, FOXJ2 can promote or suppress malignancy depending on cancer type, which may account for the colorectal carcinoma-selective association of FOXJ2-Abs (Supplementary Table S1).

CPSF2 has a suppressive role in cell invasion in thyroid cancer and cancer stem cell population [101]. It is involved in the 6-gene prognostic signature for hepatocellular carcinoma overall survival prediction [102]. Our results showed only a slight association of CPSF2-Abs with esophageal squamous cell carcinoma $(P<0.01)$ but not with other types of cancer (Supplementary Table $\mathrm{S} 1$ ). CPSF2-Ab may reflect DM-caused atherosclerosis as described above, and the causes of cancer and atherosclerosis overlap with each other. Thus, CPSF2-Abs may be associated indirectly with some types of cancer.

\section{Characteristics of antibody biomarkers}

Atherosclerosis progresses slowly over many years, finally leading to the onset of AIS or AMI. The prodromal stages of AIS and AMI may be accompanied by tissue destruction in arteries. The development of autoantibodies may be caused by high expressions of antigenic proteins in arteries followed by tissue destruction-induced exposure of antigens to immune cells. Repeated destruction/exposure can considerably increase antibody levels while keeping the antigen level low. Thus, antibody markers are much more sensitive than antigen markers. In addition, serum IgG proteins are highly stable and not easily degraded. As such, antibody markers are highly suitable for detecting trivial alterations caused by early-stage lesions. This is consistent with results that in this study, serum DIDO1$\mathrm{Ab}, \mathrm{FOXJ} 2-\mathrm{Ab}$, and CPSF2-Ab were elevated not only in patients with AIS but also in those with TIA, a prodromal lesion of AIS (Fig. 2).

AIS is a severe disease that often leads to death. Once it occurs, even without death, affected patients require a long rehabilitation period, with this disease also being the first cause of being bedridden. However, if the onset of AIS is predicted, most patients can avoid it via an appropriate treatment. Therefore, the development of highly sensitive and predictive biomarkers is eagerly expected. We discovered that serum DIDO1-Ab, FOXJ2$\mathrm{Ab}$, and CPSF2-Ab are useful in predicting the onset of AIS (Table 8), although these three markers may not be sufficient to diagnose all AIS types. AIS is a multifactorial disease, and each marker may associated with a different cause. The more biomarkers are identified, the more precise predictions can be achieved. Further investigations may be necessary for practical use.

\section{Limitation}

Although the present study suggests kidney failureassociated DIDO1-Ab, hypertension-related FOXJ2-Ab, and DM-related CPSF2-Ab markers as risk factors of AIS, further study using the increasing number of specimens is needed to verify the suggestion. Because our present study was carried out using specimens obtained from hospitals and universities in Japan, it is obscure whether our conclusion is generalized in other population. Further international collaborative research using the specimens from many countries is necessary for the practical use in the world.

\section{Conclusions}

Serum DIDO1-Ab, FOXJ2-Ab, and CPSF2-Ab appear to be useful for diagnosing AIS and may originate from kidney disease, hypertension, and DM, respectively.

\section{Abbreviations}

AIS: Acute ischemic stroke; AlphaLISA: Amplified luminescent proximity homogeneous assay-linked immunosorbent assay; AMI: Acute myocardial infarction; asympt-Cl: Asymptomatic cerebral infarction; AUC: Area under the curve; bCPSF2-607: Biotinylated peptide of CPSF2 amino acids 607-621, biotin-QVRLKDSLVSSLQFC; bDIDO1-297: Biotinylated peptide of DIDO1 amino acids 297-314, biotin-AMAASKKTAPPGSAVGKQ; bFOXJ2-426: Biotinylated peptide of FOXJ2 amino acids 426-440, biotin-KMVNRLNWSSIEQSQ; 
BMP: Bone morphogenetic protein; $\mathrm{CCl}$ : Chronic-phase cerebral infarction; $\mathrm{Cl}$ : Confidence interval; CKD: Chronic kidney disease; COPE: Coatomer protein complex subunit epsilon; CPSF2: Cleavage and polyadenylation specificity factor; CPSF2-Ab: Anti-bCPSF2-607 peptide antibody; CTEPH: Chronic thromboembolic pulmonary hypertension; CVD: Cardiovascular disease; DIDO1: Death-inducer obliterator 1; DIDO1-Ab: Anti-DIDO1 N-terminal protein antibody; DIDO1 pep-Ab: Anti-bDIDO1-297 peptide antibody; DM: Diabetes mellitus; DSWMH: Deep and subcortical white matter hyperintensity; E. coli: Escherichia coli; FOXJ2: Forkhead box J2; FOXJ2Ab: Anti-bFOXJ2-426 peptide antibody; GST: Glutathione S-transferase; HbA1c: Glycated hemoglobin; HD: Healthy donor; JPHC: Japan Public Health Center; max IMT: Maximum intima media thickness; OSA: Obstructive sleep apnea; PAH: Pulmonary arterial hypertension; PBS: Phosphate-buffered saline; ROC: Receiver operating characteristic; SD: Standard deviation; SEREX: Serological identification of antigens by cDNA expression cloning; SLE: Systemic lupus erythematosus; TGF- $\beta$ : Transforming growth factor- $\beta$; TIA: Transient ischemic attack

\section{Supplementary Information}

The online version contains supplementary material available at https://doi. org/10.1186/s12916-021-02001-9.

Additional file 1. Supplementary information.

\section{Acknowledgements}

The authors would like to thank Prof. Masaki Takiguchi and Dr. Xiao-Meng Zhang (Department of Biochemistry and Genetics, Graduate School of Medicine, Chiba University) for supporting our research, as well as Masae Suzuki, Risa Kimura, Akiko Kimura, Ryo Fukushima, Yuko Ohta, Aki Furuya, and Keiko lida for technical assistance. We also thank Dr. Takeshi Wada (Department of Internal Medicine, Chiba Aoba Municipal Hospital), Dr. Akiyo Aotsuka (Department of Internal Medicine, Chiba Aoba Municipal Hospital), Prof. Kenichiro Kitamura (Department of Internal Medicine 3, University of Yamanashi School of Medicine), Dr. Koichi Kashiwado (Department of Neurology, Kashiwado Hospital), Dr. Hideo Shin (Department of Neurosurgery, Higashi Funabashi Hospital), Dr. Takao Sugiyama (Department of Rheumatology, National Hospital Organization, Shimoshizu Hospital), and Dr. Ryutaro Matsumura (Department of Rheumatology, National Hospital Organization, Chiba-East-Hospital) for providing research materials.

\section{Authors' contributions}

$\mathrm{TH}, \mathrm{TMac}, \mathrm{EK}, \mathrm{MMo}, \mathrm{EN}$, and HKu created the concept and design of the study. HW, KG, KS, MMu, AH, MY, SKo, TA, AK, Kl, SYL, GT, NSh, and RN performed experiments and acquired data. SM, MKun, IK, AU, MO, YM, KK, HKa, RI, HT, KM, TMar, MT, YIm, TN, JT, TMatsum, YKa, AN, MI, FS, MSu, MSh, and SYO contributed to the preparing of reagents, materials, analysis tools, and data. YY, AA, TKi, YKo, MT, NK, NT, SS, TKu, HD, and HA contributed to the analysis and interpretation of the data. HW, KG, MSa, KYa, and NSa performed the statistical analyses. TH, TMac, YY, TMatsut, MKu, SYa, and YIw contributed to the drafting of the manuscript. HI, ST, SKu, KYo, FN, HM, KT, $H S$, and Ylw supervised the study. All authors gave final approval for the article to be published.

\section{Funding}

This work was supported, in part, by research grants from the Japan Science and Technology Agency (JST) in Japan, JSPS KAKENHI Grant Number 20K17953, 19K09451, 17K19810, 17K16626, 19K08596, 20K07810, 18K07387, and 16K10520, the Japan Agency for Medical Research and Development (AMED) (Practical Research Project for Life-Style related Diseases including Cardiovascular Diseases and Diabetes Mellitus), the Platform Project for Supporting in Drug Discovery and Life Science Research (Platform for Drug Discovery, Informatics, and Structural Life Science) from the Ministry of Education, Culture, Sports, Science and Technology (MEXT), Toka-Donghua Educational and Cultural Exchange Foundation, and a grant from Setsuro Fujii Memorial, the Osaka Foundation for Promotion of Fundamental Medical Research. The serum samples used for this research were provided from the BioBank Japan Project that is supported by AMED. The Japan Public Health Center-based Prospective Study was supported by National Cancer Center Research and Development Fund (since 2011) and a Grant-in-Aid for Cancer
Research from the Ministry of Health, Labour and Welfare of Japan (from 1989 to 2010).

\section{Availability of data and materials}

The datasets used and analyzed during the current study are available from the corresponding author on reasonable request.

\section{Declarations}

\section{Ethics approval and consent to participate}

This study was approved by the Local Ethical Review Board of the Chiba University Graduate School of Medicine (Chiba, Japan) as well as the review boards of the cooperating hospitals or institutes. Sera were collected from participants who had provided informed consent. The study was conducted in accordance with the principles of the Declaration of Helsinki (2013).

\section{Consent for publication}

Not applicable.

\section{Competing interests}

This work was performed in collaboration with Fujikura Kasei Co., Ltd. and Celish FD Inc. RN, GT, NS, and HK are employees of Fujikura Kasei Co., Ltd., and TK and HD are employees of Celish Fd Inc.

\section{Author details}

'Department of Neurological Surgery, Graduate School of Medicine, Chiba University, Chiba 260-8670, Japan. ${ }^{2}$ Department of Biochemistry and Genetics, Graduate School of Medicine, Chiba University, Chiba 260-8670, Japan. ${ }^{3}$ Comprehensive Stroke Center, Chiba University Hospital, Chiba 260-8677, Japan. ${ }^{4}$ Department of Anesthesia, The First Affiliated Hospital, Jinan University, Guanzhou 510632, P. R. China. ${ }^{5}$ Department of Neurological Surgery, Chiba Prefectural Sawara Hospital, Chiba 287-0003, Japan.

${ }^{6}$ Department of Neurological Surgery, Chiba Cerebral and Cardiovascular Center, Chiba 290-0512, Japan. ${ }^{7}$ Department of Neurosurgery, Eastern Chiba Medical Center, Chiba 283-8686, Japan. ${ }^{8}$ Department of Public Health Medicine, Faculty of Medicine, and Health Services Research and Development Center, University of Tsukuba, Tsukuba 305-8575, Japan. ${ }^{9}$ Department of Preventive Medicine and Public Health, Keio University School of Medicine, Tokyo 160-8582, Japan. ${ }^{10}$ Public Health, Department of Social Medicine, Osaka University Graduate School of Medicine, Suita 565-0871, Japan. "11Epidemiology and Prevention Group, Center for Public Health Sciences, National Cancer Center, Tokyo 104-0045, Japan.

${ }^{12}$ Department of Home Economics, Nagoya Women's University, Nagoya 467-8610, Japan. ${ }^{13}$ Department of Neurology, Chiba Rosai Hospital, Chiba 290-0003, Japan. ${ }^{14}$ Department of Neurology, Chibaken Saiseikai Narashino Hospital, Chiba 275-8580, Japan. ${ }^{15}$ Department of Neurology, Graduate School of Medicine, Chiba University, Chiba 260-8670, Japan. ${ }^{16}$ Department of Cardiovascular Medicine, Graduate School of Medicine, Chiba University, Chiba 260-8670, Japan. ${ }^{17}$ Department of Cardiovascular Medicine, Graduate School of Medicine, Kyoto University, Kyoto 606-8507, Japan. ${ }^{18}$ Department of Pharmacology, Shiga University of Medical Science, Shiga 520-2192, Japan.

${ }^{19}$ Department of Endocrinology, Hematology and Gerontology, Graduate

School of Medicine, Chiba University, Chiba 260-8670, Japan. ${ }^{20}$ Department of Diabetes, Metabolism and Endocrinology, School of Medicine, International University of Health and Welfare, Chiba 286-8686, Japan. ${ }^{21}$ Port Square Kashiwado Clinic, Kashiwado Memorial Foundation, Chiba 260-0025, Japan. ${ }^{22}$ Department of Molecular Pathology, Graduate School of Medicine, Chiba University, Chiba 260-8670, Japan. ${ }^{23}$ Department of Laboratory Medicine \& Division of Clinical Genetics, Chiba University Hospital, Chiba 260-8677, Japan. ${ }^{24}$ Department of Medical Technology and Sciences, School of Health Sciences at Narita, International University of Health and Welfare, Chiba 286-8686, Japan. ${ }^{25}$ Division of Clinical Genetics, Chiba Foundation for Health Promotion and Disease Prevention, Chiba 261-0002, Japan. ${ }^{26}$ Department of Frontier Surgery, Graduate School of Medicine, Chiba University, Chiba 260-8670, Japan. ${ }^{27}$ Department of Allergy and Rheumatology, Chiba Children's Hospital, Chiba 266-0007, Japan. ${ }^{28}$ Department of Gastroenterology, Graduate School of Medicine, Chiba University, Chiba 260-8670, Japan. ${ }^{29}$ Department of Respirology, Graduate School of Medicine, Chiba University, Chiba 260-8670, Japan. ${ }^{30}$ Department of Advanced Medicine in Pulmonary Hypertension, Graduate School of Medicine, Chiba University, Chiba 260-8670, Japan. ${ }^{31}$ Department of 
Gastroenterological Surgery and Clinical Oncology, Toho University Graduate School of Medicine, Tokyo 143-8541, Japan. ${ }^{32}$ Division of Structural and Synthetic Biology, RIKEN Center for Life Science Technologies, Yokohama, Kanagawa 230-0045, Japan. ${ }^{33}$ RIKEN Structural Biology Laboratory, Yokohama, Kanagawa 230-0045, Japan. ${ }^{34}$ Celish FD Inc., Chiba, Japan. ${ }^{35}$ Medical Project Division, Research Development Center, Fujikura Kasei Co., Saitama 340-0203, Japan.

Received: 12 June 2020 Accepted: 30 April 2021

Published online: 09 June 2021

\section{References}

1. Libby P, Buring JE, Badimon L, Hansson GK, Deanfield J, Bittencourt MS, et al. Atherosclerosis. Nat Rev Dis Primers. 2019;5:56. https://doi.org/10.1038/ s41572-019-0106-z PMID: 31420554

2. Valdivielso JM, Rodriguez-Puyol D, Pascual J, Barrios C, Bermúdez-López M, Sánchez-Niño MD, et al. Atherosclerosis in chronic kidney disease. Arterioscler Thromb Vasc Biol. 2019;39:1938-66. https://doi.org/10.1161/A TVBAHA.119.312705 PMID: 31412740.

3. Basatemur GL, Jørgensen HF, Clarke MCH, Bennett MR, Mallat Z. Vascular smooth muscle cells in atherosclerosis. Nat Rev Cardiol. 2019;16:727-44. https://doi.org/10.1038/s41569-019-0227-9 PMID: 31243391

4. Nelson JR, Wani O, May HT, Budoff M. Potential benefits of eicosapentaenoic acid on atherosclerotic plaques. Vascul Pharmacol. 2017; 91:1-9. https://doi.org/10.1016/j.vph.2017.02.004 PMID: 28263852.

5. Nagenborg J, Goossens P, Biessen EAL, Donners MMPC. Heterogeneity of atherosclerotic plaque macrophage origin, phenotype and functions: implications for treatment. Eur J Pharmacol. 2017;816:14-24. https://doi. org/10.1016/j.ejphar.2017.10.005 PMID: 28989084.

6. Bai MF, Wang X. Risk factors associated with coronary heart disease in women: a systematic review. Herz. 2019. https://doi.org/10.1007/s00059-01 9-4835-2 PMID: 31317202.

7. Tibaut M, Caprnda M, Kubatka P, Sinkovič A, Valentova V, Filipova S, et al. Markers of Atherosclerosis: Part 1 - Serological Markers. Heart Lung Circ. 2019;28:667-77. https://doi.org/10.1016/j.hlc.2018.06.1057 PMID: 30468147.

8. Chabriat H, Joutel A, Dichgans M, Tournier-Lasserve E, Bousser MG. Cadasil. Lancet Neurol. 2009;8:643-53. https://doi.org/10.1016/S1474-4422(09)701279 PMID: 19539236.

9. Bugiani M, Kevelam SH, Bakels HS, Waisfisz Q, Ceuterick-de Groote C, Niessen HW, et al. Cathepsin A-related arteriopathy with strokes and leukoencephalopathy (CARASAL). Neurology. 2016;87:1777-86. https://doi. org/10.1212/WNL.0000000000003251 PMID: 27664989.

10. Debette S, Goeggel Simonetti B, Schilling S, Martin JJ, Kloss M, Sarikaya H, et al. Familial occurrence and heritable connective tissue disorders in cervical artery dissection. Neurology. 2014;83:2023-31. https://doi.org/1 0.1212/WNL.0000000000001027 PMID: 25355833

11. Shimada H. p53 molecular approach to diagnosis and treatment of esophageal squamous cell carcinoma. Ann Gastroenterol Surg. 2018;2:26673. https://doi.org/10.1002/ags3.12179 PMID: 30003189.

12. Chen $Y T$, Scanlan MJ, Sahin U, Türeci $O$, Gure AO, Tsang S, et al. A testicular antigen aberrantly expressed in human cancers detected by autologous antibody screening. Proc Natl Acad Sci U S A. 1997;94:1914-8. https://doi. org/10.1073/pnas.94.5.1914 PMID: 9050879.

13. Qin JJ, Wang XR, Wang P, Ren PF, Shi JX, Zhang HF, et al. Mini-array of multiple tumor-associated antigens (TAAs) in the immunodiagnosis of esophageal cancer. Asian Pac J Cancer Prev. 2014;15:2635-40. https://doi. org/10.7314/apjcp.2014.15.6.2635 PMID: 24761876.

14. Hiwasa T, Shimada H. Autoantibody in cancer. In: Shimada H, editor. Biomarkers in Cancer Therapy (ISBN: 978-981-13-7295-7). Singapore: Springer Nature; 2019. p. 25-40. https://doi.org/10.1007/978-981-13-7295-7_3.

15. Kramer J, Harcos P, Prohászka Z, Horváth L, Karádi I, Singh M, et al. Frequencies of certain complement protein alleles and serum levels of antiheat-shock protein antibodies in cerebrovascular diseases. Stroke. 2000;31: 2648-52. https://doi.org/10.1161/01.str.31.11.2648 PMID: 11062289.

16. Palmer JP, Asplin CM, Clemons P, Lyen K, Tatpati O, Raghu PK, et al. Insulin antibodies in insulin-dependent diabetics before insulin treatment. Science. 1983;222:1337-9. https://doi.org/10.1126/science.6362005 PMID: 6362005.

17. Baekkeskov S, Aanstoot H, Christgau S, Reetz A, Solimena M, Cascalho M, et al. Identification of the $64 \mathrm{~K}$ autoantigen in insulin dependent diabetes as the GABA-synthesizing enzyme glutamic acid decarboxylase. Nature. 1990; 347:151-6. https://doi.org/10.1038/347151a0 PMID: 1697648.
18. Payton MA, Hawkes CJ, Christie MR. Relationship of the 37,000- and 40,000$M(r)$ tryptic fragments of islet antigens in insulin-dependent diabetes to the protein tyrosine phosphatase-like molecule IA-2 (ICA512). J Clin Invest. 1995; 96:1506-11. https://doi.org/10.1172/JCl118188 PMID: 7657822.

19. Taplin CE, Barker JM. Autoantibodies in type 1 diabetes. Autoimmunity. 2008;41:11-8. https://doi.org/10.1080/08916930701619169 PMID: 18176860.

20. Liang KP, Kremers HM, Crowson CS, Snyder MR, Therneau TM, Roger VL, et al. Autoantibodies and the risk of cardiovascular events. J Rheumatol. 2009;36:2462-9. https://doi.org/10.3899/jrheum.090188 PMID: 19833748.

21. Montecucco F, Vuilleumier N, Pagano S, Lenglet $S$, Bertolotto $M$, Braunersreuther $\mathrm{V}$, et al. Anti-apolipoprotein A-1 auto-antibodies are active mediators of atherosclerotic plaque vulnerability. Eur Heart J. 2011;32:41221. https://doi.org/10.1093/eurheartj/ehq521 PMID: 21224292.

22. Satta N, Vuilleumier N. Auto-antibodies as possible markers and mediators of ischemic, dilated, and rhythmic cardiopathies. Curr Drug Targets. 2015;16: 342-60. https://doi.org/10.2174/1389450115666141125122416 PMID: 25429713.

23. Fesmire J, Wolfson-Reichlin M, Reichlin M. Effects of autoimmune antibodies anti-lipoprotein lipase, anti-low density lipoprotein, and anti-oxidized low density lipoprotein on lipid metabolism and atherosclerosis in systemic lupus erythematosus. Rev Bras Reumatol. 2010;50:539-51. https://doi.org/1 0.1590/s0482-50042010000500007 PMID: 21125190.

24. Carbone F, Nencioni A, Mach F, Vuilleumier N, Montecucco F. Evidence on the pathogenic role of auto-antibodies in acute cardiovascular diseases. Thromb Haemost. 2013;109(05):854-68. 23446994. https://doi.org/10.1160/ TH12-10-0768.

25. Nakashima K, Shimada H, Ochiai T, Kuboshima M, Kuroiwa N, Okazumi S, et al. Serological identification of TROP2 by recombinant CDNA expression cloning using sera of patients with esophageal squamous cell carcinoma. Int J Cancer. 2004;112:1029-35. https://doi.org/10.1002/ijc.20517 PMID: 15386348.

26. Kuboshima M, Shimada H, Liu TL, Nomura F, Takiguchi M, Hiwasa T, et al. Presence of serum tripartite motif-containing 21 antibodies in patients with esophageal squamous cell carcinoma. Cancer Sci. 2006;97:380-6. https://doi. org/10.1111/j.1349-7006.2006.00192.x PMID: 16630135.

27. Shimada H, Shiratori T, Yasuraok M, Kagaya A, Kuboshima M, Nomura F, et al. Identification of Makorin 1 as a novel SEREX antigen of esophageal squamous cell carcinoma. BMC Cancer. 2009;9(1):232. https://doi.org/10.11 86/1471-2407-9-232. PMID: 19604354

28. Kagaya A, Shimada H, Shiratori T, Kuboshima M, Nakashima-Fujita K, Yasuraoka $M$, et al. Identification of a novel SEREX antigen family, ECSA, in esophageal squamous cell carcinoma. Proteome Sci. 2011;9(1):31. https:// doi.org/10.1186/1477-5956-9-31. PMID: 21696638.

29. Kobayashi S, Hoshino T, Hiwasa T, Satoh M, Rahmutulla B, Tsuchida S, et al. Anti-FIRs (PUF60) auto-antibodies are detected in the sera of early-stage colon cancer patients. Oncotarget. 2016;7:82493-503. https://doi.org/10.1 8632/oncotarget.12696 PMID: 27756887

30. Matsutani T, Hiwasa T, Takiguchi M, Oide T, Kunimatsu M, Saeki N, et al. Autologous antibody to src-homology 3-domain GRB2-like 1 specifically increases in the sera of patients with low-grade gliomas. J Exp Clin Cancer Res. 2012;31:85. https://doi.org/10.1186/1756-9966-31-85 PMID: 23050879.

31. Adachi-Hayama M, Adachi A, Shinozaki N, Matsutani T, Hiwasa T, Takiguchi $M$, et al. Circulating anti-filamin C antibody as a potential serum biomarker for low-grade gliomas. BMC Cancer. 2014;14(1):452. https://doi.org/10.11 86/1471-2407-14-452.

32. Hontani K, Tsuchikawa T, Hiwasa T, Nakamura T, Ueno T, Kushibiki T, et al. Identification of novel serum autoantibodies against EID3 in non-functional pancreatic neuroendocrine tumors. Oncotarget. 2017;8:106206-21. https:// doi.org/10.18632/oncotarget.22175 PMID: 29290942.

33. Hamanaka S, Nakagawa T, Hiwasa T, Ohta Y, Kasamatsu S, Ishigami H, et al. Investigation of novel biomarkers for predicting the clinical course in patients with ulcerative colitis. J Gastroenterol Hepatol. 2018;33:1975-83. https://doi.org/10.1111/jgh.14297 PMID: 29869393.

34. Muto M, Mori M, Hiwasa T, Takiguchi M, Iwadate Y, Uzawa A, et al. Novel serum autoantibodies against talin1 in multiple sclerosis: Possible pathogenetic roles of the antibodies. J Neuroimmunol. 2015;284:30-6. https://doi.org/10.1016/j.jneuroim.2015.05.005 PMID: 26025055.

35. Sugimoto K, Hiwasa T, Shibuya K, Hirano S, Beppu M, Isose S, et al. Novel autoantibodies against the proteasome subunit PMSA7 in amyotrophic lateral sclerosis. J Neuroimmunol. 2018;325:54-60. https://doi.org/10.1016/j. jneuroim.2018.09.013 PMID: 30390597. 
36. Matsumura T, Terada J, Kinoshita T, Sakurai Y, Yahaba M, Tsushima K, et al. Autoantibody against NBL1 in obstructive sleep apnea patients with cardiovascular disease. PLoS One. 2018;13:e0195015. https://doi.org/10.1371/ journal.pone.0195015 PMID: 29596467.

37. Katsumata Y, Terada J, Matsumura T, Koshikawa K, Sakao S, Tomiyoshi G, et al. Circulating anti-sorting nexins 16 antibodies as an emerging biomarker of coronary artery disease in patients with obstructive sleep apnea. Diagnostics. 2020;10:71. https://doi.org/10.3390/diagnostics10020071 PMID: 32012743

38. Naito A, Hiwasa T, Tanabe N, Jujo-Sanada T, Sugiura T, Shigeta A, et al. Elevated levels of autoantibodies against EXD2 and PHAX in the sera of patients with chronic thromboembolic pulmonary hypertension. PLoS One. 2019;14:e0211377. https://doi.org/10.1371/journal.pone.0211377 PMID: 30759165

39. Machida T, Kubota M, Kobayashi E, Iwadate Y, Saeki N, Yamaura A, et al. Identification of stroke-associated-antigens via screening of recombinant proteins from the human expression cDNA library (SEREX). J Translat Med. 2015;13:71. https://doi.org/10.1186/s12967-015-0393-4 PMID: 25890248.

40. Yoshida Y, Wang H, Hiwasa T, Machida T, Kobayashi E, Mine S, et al. Elevation of autoantibody level against PDCD11 in patients with transient ischemic attack. Oncotarget. 2018:9:8836-48. https://doi.org/10.18632/ oncotarget.23653 PMID: 29507658.

41. Wang $H$, Zhang XM, Tomiyoshi G, Nakamura R, Shinmen N, Kuroda H, et al. Association of serum levels of antibodies against MMP1, CBX1, and CBX5 with transient ischemic attack and cerebral infarction. Oncotarget. 2018;9: 5600-13. https://doi.org/10.18632/oncotarget.23789 PMID: 29464021.

42. Yoshida Y, Zhang XM, Wang H, Machida T, Mine S, Kobayashi E, et al. Elevated levels of autoantibodies against DNAJC2 in sera of patients with atherosclerotic diseases. Heliyon. 2020;6:e4661. https://doi.org/10.1016/j. heliyon.2020.e04661 PMID: 32904265.

43. Li SY, Yoshida Y, Kobayashi E, Adachi A, Hirono S, Matsutani T, et al. Association between serum anti-ASXL2 antibody levels and acute ischemic stroke, acute myocardial infarction, diabetes mellitus, chronic kidney disease and digestive organ cancer, and their possible association with atherosclerosis and hypertension. Int J Mol Med. 2020;46:1274-88. https:// doi.org/10.3892/ijmm.2020.4690 PMID: 32945427.

44. Chen PM, Ohno M, Hiwasa T, Nishi K, Saijo S, Sakamoto J, et al. Nardilysin is a promising biomarker for the early diagnosis of acute coronary syndrome. Int J Cardiol. 2017;243:1-8. https://doi.org/10.1016/j.ijcard.2017.04.047 PMID: 28747015.

45. Adams HP Jr, Bendixen BH, Kappelle LJ, Biller J, Love BB, Gordon DL, et al. Classification of subtype of acute ischemic stroke. Definitions for use in a multicenter clinical trial. TOAST. Trial of Org 10172 in Acute Stroke Treatment. Stroke. 1993;24:35-41. https://doi.org/10.1161/01.str.24.1.35 PMID: 7678184.

46. Nishiura R, Fujimoto S, Sato Y, Yamada K, Hisanaga S, Hara S, et al. Elevated osteoprotegerin levels predict cardiovascular events in new hemodialysis patients. Am J Nephrol. 2009;29:257-63. https://doi.org/10.1159/000157629 PMID: 18802328

47. Komatsu H, Fujimoto S, Hara S, Fukuda A, Fukudome K, Yamada K, et al. Recent therapeutic strategies improve renal outcome in patients with IgA nephropathy. Am J Nephrol. 2009;30:19-25. https://doi.org/10.1159/0001 97116 PMID: 19169006.

48. Goto K, Sugiyama T, Matsumura R, Zhang XM, Kimura R, Taira A, et al. Identification of cerebral infarction-specific antibody markers from autoantibodies detected in patients with systemic lupus erythematosus. J Mol Biomark Diagnos. 2015;6:-2. https://doi.org/10.4172/2155-9929.1000219.

49. Vermeulen N, de Béeck KO, Vermeire S, Van Steen K, Michiels G, Ballet V, et al. Identification of a novel autoantigen in inflammatory bowel disease by protein microarray. Inflamm Bowel Dis. 2011;17:1291-300. https://doi. org/10.1002/ibd.21508 PMID: 21560193.

50. Kato R, Kaga C, Kunimatsu M, Kobayashi T, Honda H. Peptide array-based interaction assay of solid-bound peptides and anchorage-dependent cells and its effectiveness in cell-adhesive peptide design. J Biosci Bioeng. 2006; 101:485-95. https://doi.org/10.1263/jbb.101.485 PMID: 16935250.

51. Hiwasa T, Tomiyoshi G, Nakamura R, Shinmen N, Kuroda H, Kunimatsu M, et al. Serum SH3BP5-specific antibody level is a biomarker of atherosclerosis. Immunome Res. 2017;13:132. https://doi.org/10.4172/17457580.1000132.

52. Tsugane S, Sawada N. The JPHC study: design and some findings on the typical Japanese diet. Jpn J Clin Oncol. 2014;44:777-82. https://doi.org/10.1 093/jjco/hyu096 PMID: 25104790.
53. Ikeda A, Iso H, Sasazuki S, Inoue M, Tsugane S, JPHC Study Group. The combination of Helicobacter pylori- and cytotoxin-associated gene-A seropositivity in relation to the risk of myocardial infarction in middle-aged Japanese: The Japan Public Health Center-based study. Atherosclerosis. 2013; 230(1):67-72. 23958254. https://doi.org/10.1016/j.atherosclerosis.2013.06.013.

54. Hiwasa T, Machida T, Zhang XM, Kimura R, Wang H, Iwase K, et al. Elevated levels of autoantibodies against ATP2B4 and BMP-1 in sera of patients with atherosclerosis-related diseases. Immunome Res. 2015;11:097. https://doi. org/10.4172/1745-7580.1000097.

55. Nakamura R, Tomiyoshi G, Shinmen N, Kuroda H, Kudo T, Doi H, et al. An anti-deoxyhypusine synthase antibody as a marker of atherosclerosis-related cerebral infarction, myocardial infarction, diabetes mellitus, and chronic kidney disease. SM Atheroscler J. 2017;1:1001. http://smjournals.com/a therosclerosis/in-press.php\#x.

56. Hiwasa T, Zhang XM, Kimura R, Machida T, Kitamura K, Yamazoe R, et al. Association of serum antibody levels against TUBB2C with diabetes and cerebral infarction. Integ Biomed Sci. 2015;1:49-63. https://doi.org/10.18314/ gjbs.v1i2.27.

57. Sumazaki M, Shimada H, Ito M, Shiratori F, Kobayashi E, Yoshida $Y$, et al. Serum anti-LRPAP1 is a common biomarker for digestive organ cancers and atherosclerotic diseases. Cancer Sci. 2020;111(12):4453-64. 32939876. https:// doi.org/10.1111/cas.14652.

58. Yoshida Y, Hiwasa T, Machida T, Kobayashi E, Mine S, Matsushima J, et al. Elevation of autoantibody in patients with ischemic stroke. Neurol Med Chir (Tokyo). 2018;58:303-10. https://doi.org/10.2176/nmc.ra.2018-0022 PMID: 29848906.

59. Sugimoto K, Tomiyoshi G, Mori M, Kuwabara S, Hirano S, Sawai S, et al. Identification of serum anti-GADD34 antibody as a common marker of diabetes mellitus and Parkinson disease. J Alzheimers Dis Parkinsonism. 2017;7(04):358. https://doi.org/10.4172/2161-0460.1000358.

60. Zhang XM, Wang H, Mine S, Takemoto M, Yokote K, Kitamura K, et al. Association of serum anti-prolylcarboxypeptidase antibody marker with atherosclerotic diseases accompanied by hypertension. J Mol Biomark Diagn. 2017;8(06):361. https://doi.org/10.4172/2155-9929.1000361.

61. Wolfe F, Freundlich B, Straus WL. Increase in cardiovascular and cerebrovascular disease prevalence in rheumatoid arthritis. J Rheumatol. 2003;30(1):36-40. 12508387.

62. Symmons DP, Gabriel SE. Epidemiology of CVD in rheumatic disease, with a focus on RA and SLE. Nat Rev Rheumatol. 2011;7:399-408. https://doi.org/1 0.1038/nrrheum.2011.75 PMID: 21629241.

63. Carbone F, Bonaventura A, Liberale L, Paolino S, Torre F, Dallegri F, et al. Atherosclerosis in rheumatoid arthritis: promoters and opponents. Clin Rev Allergy Immunol. 2020;58:1-14. https://doi.org/10.1007/s12016-018-8714-z PMID: 30259381.

64. Sanjadi M, Rezvanie Sichanie Z, Totonchi H, Karami J, Rezaei R, Aslani S. Atherosclerosis and autoimmunity: a growing relationship. Int J Rheum Dis. 2018;21:908-21. https://doi.org/10.1111/1756-185X.13309 PMID: 29671956.

65. Matsumura T, Terada J, Kinoshita T, Sakurai Y, Yahaba M, Ema R, et al. Circulating anti-coatomer protein complex subunit epsilon (COPE) autoantibodies as a potential biomarker for cardio- and cerebrovascular events in patients with obstructive sleep apnea. J Clin Sleep Med. 2017;13:393-400. https://doi.org/10.5664/jcsm.6488 PMID: 27923433.

66. Naito A, Tanabe N, Jujo T, Shigeta A, Sugiura T, Sakao S, et al. Pentraxin3 in chronic thromboembolic pulmonary hypertension: a new biomarker for screening from remitted pulmonary thromboembolism. PLoS One. 2014;9: e113086. https://doi.org/10.1371/journal.pone.0113086 PMID: 25412085.

67. Tran LT, Park HJ, Kim HD. Is the carotid intima-media thickness really a good surrogate marker of atherosclerosis? J Atheroscler Thromb. 2012;19(7):68090. 22653163. https://doi.org/10.5551/jat.11767.

68. Zureik M, Ducimetière P, Touboul PJ, Courbon D, Bonithon-Kopp C, Berr C, et al. Common carotid intima-media thickness predicts occurrence of carotid atherosclerotic plaques: Iongitudinal results from the Aging Vascular Study (EVA) study. Arterioscler Thromb Vasc Biol. 2000;20(6):1622-9. 1084 5881. https://doi.org/10.1161/01.atv.20.6.1622.

69. Koivistoinen T, Virtanen M, Hutri-Kähönen N, Lehtimäki T, Jula A, Juonala M, et al. Arterial pulse wave velocity in relation to carotid intima-media thickness, brachial flow-mediated dilation and carotid artery distensibility: the Cardiovascular Risk in Young Finns Study and the Health 2000 Survey. Atherosclerosis. 2012;220(2):387-93. https://doi.org/10.1016/j.a therosclerosis.2011.08.007. PMID: 21871623. 
70. Mannami T, Konishi M, Baba S, Nishi N, Terao A. Prevalence of asymptomatic carotid atherosclerotic lesions detected by high-resolution ultrasonography and its relation to cardiovascular risk factors in the general population of a Japanese city: the Suita study. Stroke. 1997;28(3):518-25. https://doi.org/10.1161/01.str.28.3.518. PMID: 9056605.

71. Garcia-Domingo D, Leonardo E, Grandien A, Martinez P, Albar JP, IzpisuaBelmonte JC, et al. DIO-1 is a gene involved in onset of apoptosis in vitro, whose misexpression disrupts limb development. Proc Nat Acad Sci USA. 1999;96:7992-7. https://doi.org/10.1073/pnas.96.14.7992 PMID: 10393935.

72. Pérez-Sánchez C, Gómez-Ferrería MA, de La Fuente CA, Granadino B, Velasco G, Esteban-Gamboa A, et al. FHX, a novel fork head factor with a dual DNA binding specificity. J Biol Chem. 2000;275:12909-16. https://doi. org/10.1074/jbc.275.17.12909 PMID: 10777590.

73. Soriano LC, Soriano-Gabarró M, García Rodríguez LA. Trends in the contemporary incidence of colorectal cancer and patient characteristics in the United Kingdom: a population-based cohort study using The Health Improvement Network. BMC Cancer. 2018;18:402. https://doi.org/10.1186/ s12885-018-4265-1 PMID: 29636012.

74. Qian J, Li M, Zhang X, Wang Q, Zhao J, Tian Z, et al. Long-term prognosis of patients with systemic lupus erythematosus-associated pulmonary arterial hypertension: CSTAR-PAH cohort study. Eur Respir J. 2019;53:1800081. https://doi.org/10.1183/13993003.00081-2018 PMID: 30635295.

75. Murthy KGK, Manley JL. The $160-k D$ subunit of human cleavagepolyadenylation specificity factor coordinates pre-mRNA 3-prime-end formation. Genes Dev. 1995;9:2672-83. https://doi.org/10.1101/gad.9.21.2672 PMID: 7590244.

76. Cai J, Pardali E, Sánchez-Duffhues G, ten Dijke P. BMP signaling in vascular diseases. FEBS Lett. 2012;586:1993-2002. https://doi.org/10.1016/j.febslet.2 012.04.030 PMID: 22710160.

77. Dyer LA, Pi X, Patterson C. The role of BMPs in endothelial cell function and dysfunction. Trends Endocrinol Metab. 2014;25:472-80. https://doi.org/10.1 016/j.tem.2014.05.003 PMID: 24908616.

78. Dhore CR, Cleutjens JP, Lutgens E, Cleutjens KB, Geusens PP, Kitslaar PJ, et al. Differential expression of bone matrix regulatory proteins in human atherosclerotic plaques. Arterioscler Thromb Vasc Biol. 2001;21:1998-2003. https://doi.org/10.1161/hq1201.100229 PMID: 11742876.

79. Sorescu GP, Sykes M, Weiss D, Platt MO, Saha A, Hwang J, et al. Bone morphogenic protein 4 produced in endothelial cells by oscillatory shear stress stimulates an inflammatory response. J Biol Chem. 2003;278:31128-35. https://doi.org/10.1074/jbc.M300703200 PMID: 12766166.

80. Zhang M, Sara JD, Wang FL, Liu LP, Su LX, Zhe J, et al. Increased plasma BMP-2 levels are associated with atherosclerosis burden and coronary calcification in type 2 diabetic patients. Cardiovasc Diabetol. 2015;14:64. https://doi.org/10.1186/s12933-015-0214-3 PMID: 26003174

81. Miriyala S, Gongora Nieto MC, Mingone C, Smith D, Dikalov S, Harrison DG, et al. Bone morphogenic protein-4 induces hypertension in mice: role of noggin, vascular NADPH oxidases, and impaired vasorelaxation. Circulation. 2006;113:2818-25. https://doi.org/10.1161/CIRCULATIONAHA.106.611822 PMID: 16769910

82. Yao Y, Bennett BJ, Wang X, Rosenfeld ME, Giachelli C, Lusis AJ, et al. Inhibition of bone morphogenetic proteins protects against atherosclerosis and vascular calcification. Circ Res. 2010;107:485-94. https://doi.org/10.1161/ CIRCRESAHA.110.219071 PMID: 20576934.

83. Derwall M, Malhotra R, Lai CS, Beppu Y, Aikawa E, Seehra JS, et al. Inhibition of bone morphogenetic protein signaling reduces vascular calcification and atherosclerosis. Arterioscler Thromb Vasc Biol. 2012;32:613-22. https://doi. org/10.1161/ATVBAHA.111.242594 PMID: 22223731.

84. Kim CW, Song H, Kumar S, Nam D, Kwon HS, Chang KH, et al. Antiinflammatory and antiatherogenic role of BMP receptor II in endothelial cells. Arterioscler Thromb Vasc Biol. 2013;33:1350-9. https://doi.org/10.11 61/ATVBAHA.112.300287 PMID: 23559633.

85. Braig S, Bosserhoff AK. Death inducer-obliterator 1 (Dido1) is a BMP target gene and promotes BMP-induced melanoma progression. Oncogene. 2013; 32:837-48. https://doi.org/10.1038/onc.2012.115 PMID: 22469980.

86. Collart C, Remacle JE, Barabino S, van Grunsven LA, Nelles L, Schellens A, et al. Smicl is a novel Smad interacting protein and cleavage and polyadenylation specificity factor associated protein. Genes Cells. 2005;10: 897-906. https://doi.org/10.1111/j.1365-2443.2005.00887.x PMID: 16115198

87. Conidi A, Cazzola S, Beets K, Coddens K, Collart C, Cornelis F, et al. Few Smad proteins and many Smad-interacting proteins yield multiple functions and action modes in TGF $\beta / B M P$ signaling in vivo. Cytokine Growth Factor Rev. 2011;22:287-300. https://doi.org/10.1016/j.cytogfr.2011.11.006 PMID: 22119658.

88. Liu Y, Kim H, Liang J, Lu W, Ouyang B, Liu D, et al. The death-inducer obliterator 1 (Dido1) gene regulates embryonic stem cell self-renewal. J Biol Chem. 2014;289:4778-86. https://doi.org/10.1074/jbc.M113.486290 PMID: 24347171.

89. Fütterer A, de Celis J, Navajas R, Almonacid L, Gutiérrez J, Talavera-Gutiérrez $A$, et al. DIDO as a switchboard that regulates self-renewal and differentiation in embryonic stem cells. Stem Cell Reports. 2017;8:1062-75. https://doi.org/10.1016/j.stemcr.2017.02.013 PMID: 28330622.

90. Allahverdian S, Chaabane C, Boukais K, Francis GA, Bochaton-Piallat ML. Smooth muscle cell fate and plasticity in atherosclerosis. Cardiovasc Res. 2018;114:540-50. https://doi.org/10.1093/cvr/cvy022 PMID: 29385543.

91. Zuccotti M, Merico V, Sacchi L, Bellone M, Brink TC, Stefanelli M, et al. Oct-4 regulates the expression of Stella and Foxj2 at the Nanog locus: implications for the developmental competence of mouse oocytes. Hum Reprod. 2009;24:2225-37. https://doi.org/10.1093/humrep/dep191 PMID: 19477878.

92. Martín-de-Lara F, Sánchez-Aparicio P, de la Fuente CA, Rey-Campos J. Biological effects of FoxJ2 over-expression. Transgenic Res. 2008;17:1131-41. https://doi.org/10.1007/s11248-008-9214-3 PMID: 18726704.

93. Yang Q, Cao X, Tao G, Zhou F, Zhao P, Shen Y, et al. Effects of FOXJ2 on TGF- $\beta 1$-induced epithelial-mesenchymal transition through Notch signaling pathway in non-small lung cancer. Cell Biol Int. 2017;41:79-83. https://doi. org/10.1002/cbin.10680 PMID: 27611107.

94. Radišauskas R, Kuzmickienè I, Milinavičienè E, Everatt R. Hypertension, serum lipids and cancer risk: a review of epidemiological evidence. Medicina [Kaunas]. 2016;52:89-98. https://doi.org/10.1016/j.medici.2016.03.002 PMID: 27170481.

95. Shan Y, Chang T, Shi S, Tang M, Bao L, Li L, et al. Foxj2 overexpression is associated with poor prognosis, progression, and metastasis in nasopharyngeal carcinoma. Onco Targets Ther. 2017;10:3733-41. https://doi. org/10.2147/OTT.S134915 PMID: 28769576.

96. Kaneda H, Arao T, Tanaka K, Tamura D, Aomatsu K, Kudo K, et al. FOXQ1 is overexpressed in colorectal cancer and enhances tumorigenicity and tumor growth. Cancer Res. 2010;70:2053-63. https://doi.org/10.1158/0008-5472.CA N-09-2161 PMID: 20145154.

97. Qiang Y, Wang F, Yan S, Zhang H, Zhu L, Chen Z, et al. Abnormal expression of Forkhead Box J2 (FOXJ2) suppresses migration and invasion in extrahepatic cholangiocarcinoma and is associated with prognosis. Int J Oncol. 2015;46:2449-58. https://doi.org/10.3892/ijo.2015.2957 PMID: 25873280.

98. Zhang H, Tang QF, Sun MY, Zhang CY, Zhu JY, Shen YL, et al. ARHGAP9 suppresses the migration and invasion of hepatocellular carcinoma cells through up-regulating FOXJ2/E-cadherin. Cell Death Dis. 2018;9:916. https:// doi.org/10.1038/s41419-018-0976-0 PMID: 30206221.

99. Qiu X, Ji B, Yang L, Huang Q, Shi W, Ding Z, et al. The role of FoxJ2 in the migration of human glioma cells. Pathol Res Pract. 2015;211:389-97. https:// doi.org/10.1016/j.prp.2015.01.005 PMID: 25661068.

100. Wang Y, Yang S, Ni Q, He S, Zhao Y, Yuan Q, et al. Overexpression of forkhead box J2 can decrease the migration of breast cancer cells. J Cell Biochem. 2012;113:2729-37. https://doi.org/10.1002/jcb.24146 PMID: 22441887.

101. Nilubol N, Boufraqech M, Zhang L, Kebebew E. Loss of CPSF2 expression is associated with increased thyroid cancer cellular invasion and cancer stem cell population, and more aggressive disease. J Clin Endocrinol Metab. 2014; 99:E1173-82. https://doi.org/10.1210/jc.2013-4140 PMID: 24654752.

102. Wang Z, Teng D, Li Y, Hu Z, Liu L, Zheng H. A six-gene-based prognostic signature for hepatocellular carcinoma overall survival prediction. Life Sci. 2018;203:83-91. https://doi.org/10.1016/j.lfs.2018.04.025 PMID: 29678742.

\section{Publisher's Note}

Springer Nature remains neutral with regard to jurisdictional claims in published maps and institutional affiliations. 